University of South Florida

DIGITAL COMMONS

Digital Commons @ University of

@ UNIVERSITY OF SOUTH FLORIDA

South Florida

$1-1-2000$

\title{
Equatorial Upwelling in the Central Pacific Estimated from Moored Velocity Profilers
}

Robert $\mathrm{H}$. Weisberg

University of South Florida, weisberg@marine.usf.edu

Lin Qiao

University of South Florida

Follow this and additional works at: https://digitalcommons.usf.edu/msc_facpub

Part of the Marine Biology Commons

\section{Scholar Commons Citation}

Weisberg, Robert H. and Qiao, Lin, "Equatorial Upwelling in the Central Pacific Estimated from Moored Velocity Profilers" (2000). Marine Science Faculty Publications. 149.

https://digitalcommons.usf.edu/msc_facpub/149

This Article is brought to you for free and open access by the College of Marine Science at Digital Commons @ University of South Florida. It has been accepted for inclusion in Marine Science Faculty Publications by an authorized administrator of Digital Commons @ University of South Florida. For more information, please contact digitalcommons@usf.edu. 


\title{
Equatorial Upwelling in the Central Pacific Estimated from Moored Velocity Profilers
}

\author{
Robert H. Weisberg AND Lin Qiao \\ Department of Marine Science, University of South Florida, St. Petersburg, Florida
}

(Manuscript received 9 March 1998, in final form 16 February 1999)

\begin{abstract}
Horizontal divergence and vertical velocity $(w)$ are estimated at $0^{\circ}, 140^{\circ} \mathrm{W}$ using an array of five subsurface moored acoustic Doppler current profilers deployed from May 1990 to June 1991 during the Tropical Instability Wave Experiment. The record-length mean flow is divergent within the near-surface region and convergent within the thermocline, with maximum convergence located at the high speed core of the Equatorial Undercurrent (EUC). This pattern of divergence results in upwelling at and above the EUC core (with maximum value of $2.3 \times 10^{-5} \mathrm{~m} \mathrm{~s}^{-1}$ located at $60-\mathrm{m} \mathrm{depth}$ ) and downwelling below the core. The relative slopes in the zonal plane between the mean velocity vectors and the isotherms suggest a net diffusive heat flux. Assuming that this occurs vertically, an entrainment velocity parameterization provides an estimate of the "diapycnal vertical velocity" profile that reverses sign at the EUC core depth. Several kinematical and dynamical consistency checks are developed on both the time-dependent and the mean motions to supplement a discussion of errors for the mean $w$ profile. The time-dependent fluctuations in $w$ may be an order of magnitude larger than the mean values, and on synoptic timescales $w$ may be directed either up or down over the entire upper 250-m region sampled.
\end{abstract}

\section{Introduction}

Easterly winds acting upon a bounded equatorial ocean cause the surface to slope so that the resulting pressure gradient force opposes the wind-induced vertical stress divergence. Due to the planetary $\beta$ effect, poleward Ekman transports cause the near-surface currents to be divergent (e.g., Cromwell 1953), which is counteracted by a zonal pressure-gradient-induced geostrophic convergence. The ensuing circulation, consisting of a westward flowing South Equatorial Current (SEC) at the surface and an eastward flowing Equatorial Undercurrent (EUC) within the thermocline, is fully three-dimensional, and these zonally oriented currents are linked by the circulation in the meridional plane (e.g., Defant 1981; Fofonoff and Montgomery 1955). Stommel (1960) provided a theory for this linkage, and Knauss (1966) provided observational evidence on how the meridional circulation cell feeds the near-surface equatorial upwelling. Such upwelling maintains the sea surface temperature (SST) gradients of the Tropics that in turn control the air-sea interactions there (Bjerknes 1966). Since tropical air-sea interactions determine global climate variations on interannual timescales [e.g., the El Niño-Southern Oscillation (ENSO: e.g., Philan-

Corresponding author address: Dr. Robert H. Weisberg, Dept. of Marine Science, University of South Florida, St. Petersburg, FL 33701.

E-mail: weisberg@ocg6.marine.usf.edu der 1990)], a better quantitative understanding of the fully three-dimensional equatorial ocean circulation is necessary for improved climate prediction by coupled ocean-atmosphere models.

As part of a study on planetary waves seasonally generated by unstable, near-surface equatorial currents, a subsurface array of acoustic Doppler current profilers (ADCP) was deployed about $0^{\circ}, 140^{\circ} \mathrm{W}$ from May 1990 to June 1991. Data from this Tropical Instability Wave Experiment (TIWE) are used to estimate the vertical component of velocity $(w)$ through vertical integration of the continuity equation. Such a procedure has been used in several previous studies but not with high vertical resolution, nor with an array that provides for center differencing.

The paper is organized as follows. Section 2 reviews background material on equatorial upwelling and previous estimates made with either in situ data or with numerical circulation models. Section 3 presents the field program, a description of the data, the method of $w$ estimation, and an overview of the various error sources. The record-length mean findings are developed in section 4. Section 5 then discusses supporting evidence in the form of kinematical and dynamical consistency checks drawn from both the time-dependent and the mean motions. Comparisons with previous results are discussed in section 6, along with implications of these findings for SST and other material property distributions. An appendix provides additional error analyses. 


\section{Background}

Poleward Ekman transports driven by easterly winds can extend into midlatitudes (e.g., Levitus 1988). As fluid moves equatorward geostrophically in compensation for this, conservation of potential vorticity requires the pycnocline to rise and the density gradient across it to increase. Additionally, the zonal slope of the pycnocline supported along the equator by easterly wind stress suggests that fluid moving eastward within the EUC rises en route. Equatorial upwelling therefore has a well-established, large-scale basis, the most obvious manifestation of which is the equatorial cold tongue. Satellite imagery shows the cold tongue to be tightly confined to and symmetric about the equator, particularly west of $110^{\circ} \mathrm{W}$ in the Pacific Ocean (Reynolds and Smith 1994). Despite this, and other measurable effects of upwelling on material properties within the equatorial region, the smallness of $w$ makes direct measurements of it difficult. Equatorial upwelling has been estimated indirectly by diagnostic calculations using linear dynamics, vertical integration of the continuity equation, or through the application of primitive equation, global circulation models.

Before reviewing previous $w$ estimations an orientation to the regional hydrography is useful. Repeated meridional sections in the central Pacific between $17^{\circ} \mathrm{S}$ and $20^{\circ} \mathrm{N}$ from the Hawaii to Tahiti Shuttle program (Wyrtki and Kilonsky 1984) show average distributions of the zonal component of velocity, temperature, salinity, oxygen, nitrate, phosphate, and silicate. Common to all of these dynamically active or passive tracers is a rising of isopleths toward the equator within the region of the thermocline. Within a few degrees of the equator and coincident with the EUC that is positioned within the thermocline is an upward (downward) bowing of material property isopleths above (below) the EUC core. The dynamically passive tracers bow downward much more steeply than the dynamically active ones in the thermostad region beneath the EUC, suggestive of large vertical mixing there. Knauss (1966) from a similar (but less comprehensively sampled) suite of hydrographic measurement surmised that downwelling and mixing occurs below the EUC core, as contrasted with upwelling and mixing above the core.

Common to most near-equator estimates of $w$ is a magnitude of a few meters per day and an upwelling maximum situated between the EUC core and the surface. The vertical distribution of $w$ and its meridional extent, however, vary largely with estimation technique. In a diagnostic study using historical hydrographic data for a box bounded by $5^{\circ} \mathrm{N}$ and $5^{\circ} \mathrm{S}, 150^{\circ} \mathrm{W}$ and $110^{\circ} \mathrm{W}$ between $500 \mathrm{db}$ and the surface, Bryden and Brady (1985) used geostrophy and an assumed Ekman transport distribution to estimate a $w$ profile on the equator. Upwelling was found across the entire EUC above 180-m depth, with smaller downwelling below. The flow within the EUC was described as being primarily along isopycnals. Maximum upwelling of magnitude $3 \times 10^{-5}$ $\mathrm{m} \mathrm{s}^{-1}$ was calculated above the EUC core at the base of the mixed layer. Halpern and Freitag (1987) and Halpern et al. (1989) using moored current meter observations near $110^{\circ} \mathrm{W}$, and at different zonal separations between $140^{\circ} \mathrm{W}$ and $110^{\circ} \mathrm{W}$, respectively, obtained results similar to Bryden and Brady (1985). Upwelling of magnitude of $2-3\left(\times 10^{-5} \mathrm{~m} \mathrm{~s}^{-1}\right)$ was found across the EUC, with maximum values either in or above the EUC core. Equatorial Atlantic Ocean calculations by Gouriou and Reverdin (1992) combining shipboard hydrography and velocity profiles also produced results similar to Bryden and Brady (1985) in both magnitude and vertical distribution. Contrary to Gouriou and Reverdin (1992), Weingartner and Weisberg (1991a) using moored current meters found a reversal from upwelling within and above the EUC core (maximum at the base of the mixed layer) to downwelling over the lower portion of the EUC. All of the time series studies using moored current meters share a common finding that $w$ is highly time dependent. Other estimates of $w$ are also available by considerations of large-scale mass balances (e.g., Wyrtki 1981; Roemmich 1983; Wunsch 1984a; Johnson and Luther 1994), tracer distributions (e.g., Broecker et al. 1978; Quay 1983; Fine et al. 1983; Wunsch 1984b), isotherm depth variations (e.g., Wyrtki and Eldin 1982), and by the estimates of horizontal divergence from surface drifters (e.g., Hansen and Paul 1984, 1987; Poulain 1993). The existence of equatorial upwelling (after averaging out synoptic and equatorial wave adjustment process variability) is unequivocal. At issue, however, is the vertical distribution of $w$, especially downwelling below the EUC core and how this bears upon material property and momentum balances. Numerical model estimates are of little help in clarifying this issue since the structure of the fully three-dimensional circulation is dependent upon turbulence parameterization. The same discrepancies found in the data analyses to date also exist in the numerical models, for example, compare Philander et al. (1987) or Harrison (1996) with Seager and Murtugudde (1997).

\section{Field program and methods}

\section{a. The TIWE equatorial array}

The TIWE equatorial array (Fig. 1) consisted of five subsurface moorings (designated TIW1-TIW5), each with an RD Instruments, Inc., $150-\mathrm{kHz} \mathrm{ADCP}$ and a Sea-Bird Electronics, Inc., SEACAT conductivity, temperature, and depth recorder. Mooring locations, record lengths, and nominal instrument depths are given in Table 1. The ADCPs with $20^{\circ}$ transducer configuration yielded hourly velocity profiles at nominal $8.67-\mathrm{m}$ intervals, roughly between $250 \mathrm{~m}$ and the surface. After applying sound speed corrections and editing for surface affects, these velocity profiles were resampled at $10-\mathrm{m}$ intervals between $250 \mathrm{~m}$ and $30 \mathrm{~m}$ by linear interpo- 


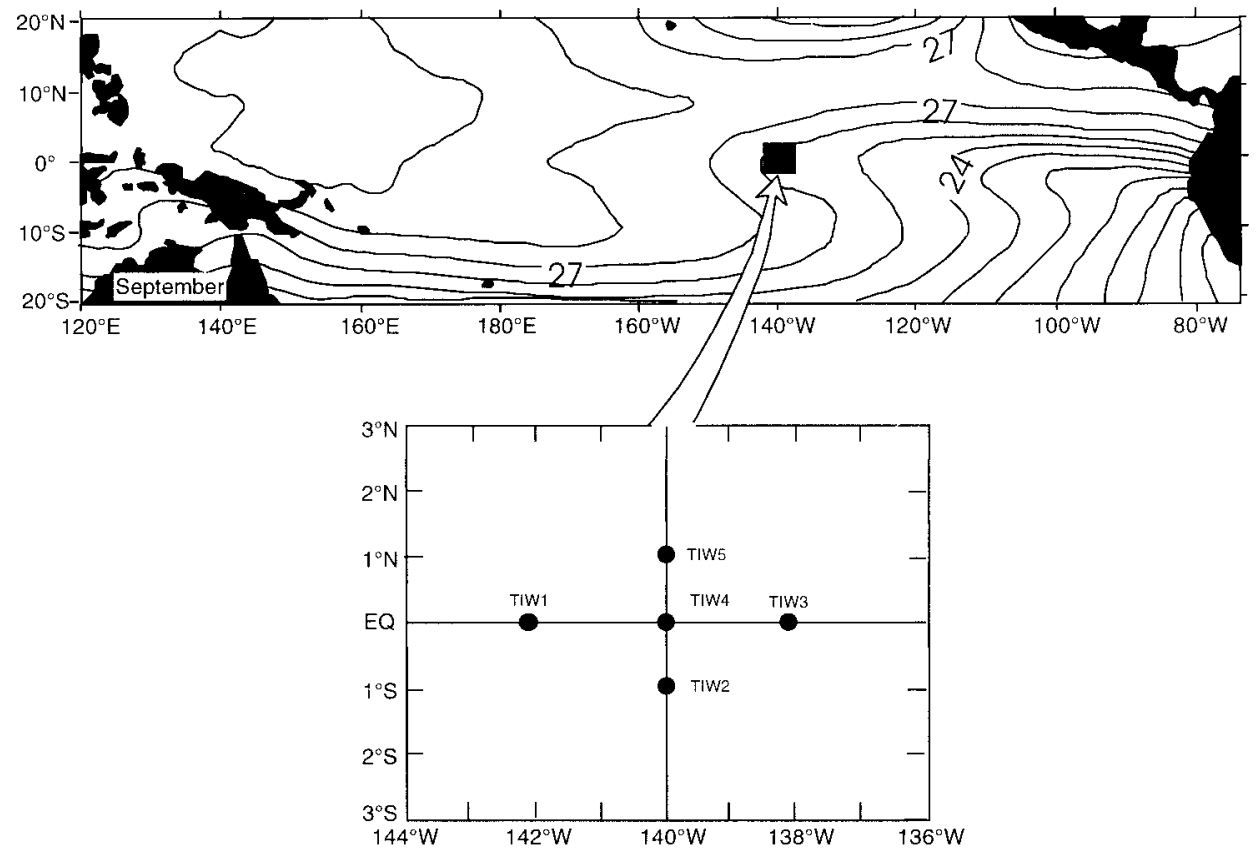

- : UNIVERSITY OF SOUTH FLORIDA, TIWE MOORINGS

FIG. 1. The TIWE equatorial array in relationship to the tropical Pacific Ocean's climatological SST distribution for September (climatology courtesy of M. McCarty and M. McPhaden, NOAA/PMEL).

lation. The 30-m bin was the closest one to the surface found to be unbiased by surface reflection. Velocity estimates above $30 \mathrm{~m}$ were made by linearly extrapolating the shear observed between $40 \mathrm{~m}$ and $30 \mathrm{~m}$ to the surface. Comparing the 20-m (nominally biased) sample with the linear extrapolation generally showed good agreement. Further information on the mooring's performance (all were stable with rms vertical excursions of only a few meters) and data editing procedures are reported in Weisberg et al. (1991). Since this paper focuses on mean fields and the low-frequency variations, all of the time series presented are low-pass filtered with a cutoff periodicity of 10 days using a truncated Fourier transform.

TABLE 1. TIWE equatorial array mooring positions and nominal instrument depths.

\begin{tabular}{lcc}
\hline \hline Mooring name & Position (lat/long) & $\begin{array}{c}\text { Instrument depth } \\
(\mathrm{m})\end{array}$ \\
\hline TIW1 & $0^{\circ} 01.4^{\prime} \mathrm{N}$ & 273.6 \\
& $141^{\circ} 50.6^{\prime} \mathrm{W}$ & \\
TIW2 & $0^{\circ} 57.8^{\prime} \mathrm{S}$ & 280.5 \\
& $139^{\circ} 57.5^{\prime} \mathrm{W}$ & \\
TIW3 & $0^{\circ} 02.4^{\prime} \mathrm{N}$ & 281.5 \\
& $137^{\circ} 57.7^{\prime} \mathrm{W}$ & \\
TIW4 & $0^{\circ} 03.2^{\prime} \mathrm{S}$ & 276.5 \\
& $140^{\circ} 08.4^{\prime} \mathrm{W}$ & 266.4 \\
TIW5 & $1^{\circ} 01.5^{\prime} \mathrm{N}$ & \\
& $139^{\circ} 57.4^{\prime} \mathrm{W}$ & \\
\hline
\end{tabular}

\section{b. The horizontal velocity measurements}

The evolution of the three-dimensional velocity vector at the center of the TIWE array may be described in the context of an annual cycle. Upper-ocean variability at this central Pacific $0^{\circ}, 140^{\circ} \mathrm{W}$ site is subject to both western and eastern Pacific influences. The annual march of the ITCZ over the eastern side of the basin (e.g., Mitchell and Wallace 1992) results in maximum (minimum) trade winds over the cold tongue region in late boreal summer to fall (late boreal winter to spring). This causes the surface westward flowing SEC and the subsurface eastward flowing EUC to vary such that westward (eastward) currents tend to be maximum when the southeast trades are strongest (weakest). For the period of the TIWE observations, local wind measurements from the TAO array (Fig. 5) show minimum easterlies during June and July 1990, relatively strong easterlies from August 1990 to February 1991, and relatively weak easterlies again during May and June 1991. Along with the annual cycle of the trade winds at $0^{\circ}$, $140^{\circ} \mathrm{W}$ the ocean response there is also affected by the integrated effects of the winds to both the east and the west (e.g., Yang et al. 1997). For instance, annual variability at $0^{\circ}, 140^{\circ} \mathrm{W}$ originating from the western Pacific warm pool region includes reversing zonal current pulses forced by westerly wind bursts that generally occur in boreal winter west of the date line (e.g., Lau and Chan 1985). The ocean's response to these wind bursts propagates eastward in the form of equatorial Kelvin 

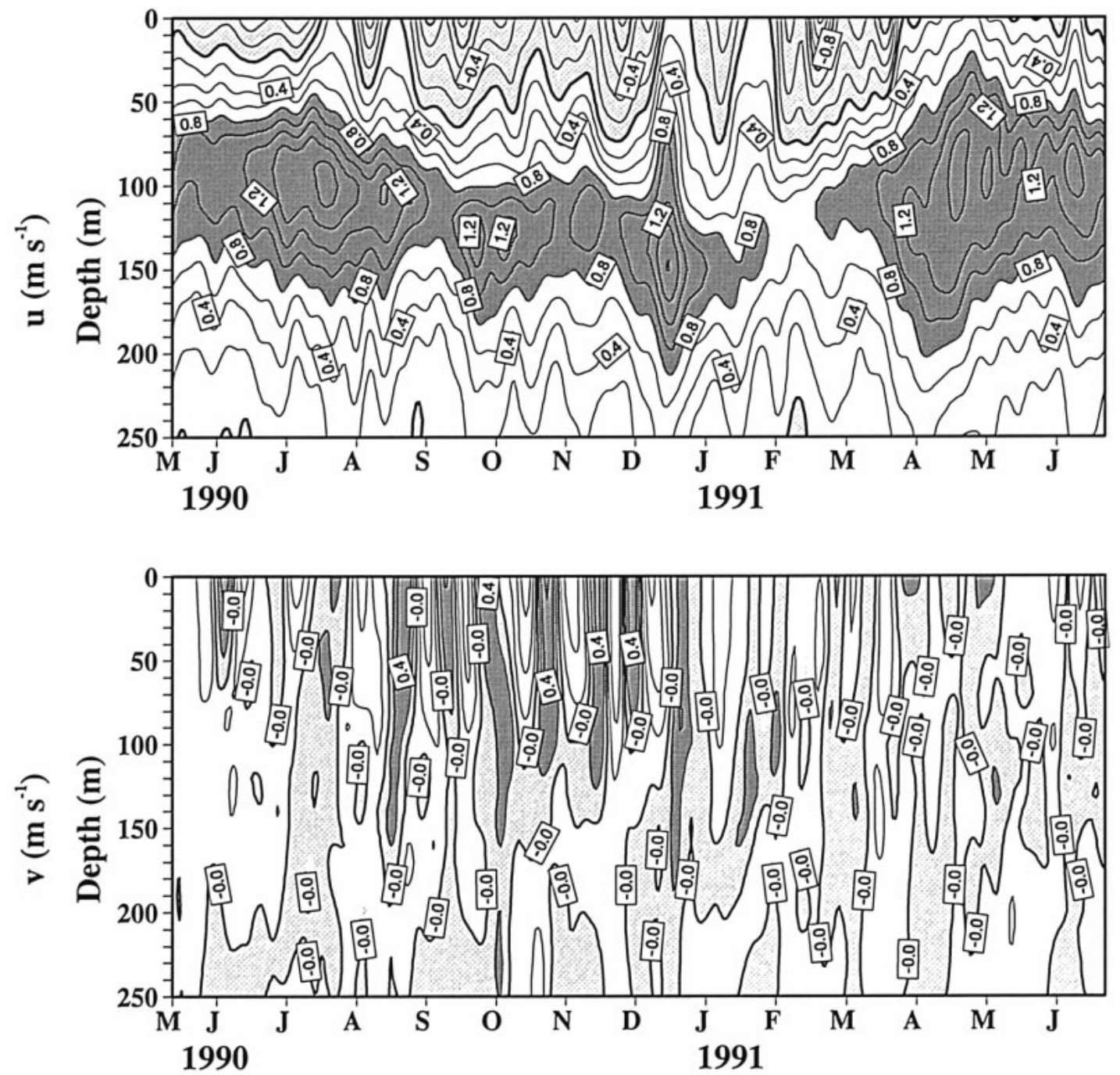

FIG. 2. The $u$ and $v$ (lower panel) components as functions of time and depth at $0^{\circ}, 140^{\circ} \mathrm{W}$. The data are low-pass filtered to remove oscillations at timescales shorter than 10 days, and the isotach contour interval is $0.2 \mathrm{~m} \mathrm{~s}^{-1}$. For the upper panel light stippling denotes the westward flowing SEC and dark stippling denotes eastward flow within the EUC in excess of $0.8 \mathrm{~m} \mathrm{~s}^{-1}$. For the lower panel, stippling denotes northward flow.

waves (Knox and Halpern 1982). More complete descriptions of the ocean's annual cycle in the central equatorial Pacific may be found in Philander et al. (1987) and McPhaden and Taft (1988). Halpern and Weisberg (1989) draw comparisons between this region and the central equatorial Atlantic, and Kessler et al. (1995) discusses more recent observations of equatorial Kelvin waves.

The zonal $(u)$ and meridional $(v)$ components of velocity measured at the TIW4 mooring near $0^{\circ}, 140^{\circ} \mathrm{W}$ are shown in Fig. 2, with isotachs contoured as a function of time (May 1990-June 1991) and depth (the upper $250 \mathrm{~m}$ of the water column). For the $u$ component, the lightly stippled region near the surface denotes the westward flowing SEC that is observed to be intermittent, extending down to $60-\mathrm{m}$ depth. Elsewhere the flow is eastward. The EUC core (defined by $\partial u / \partial z=0$ ) region, denoted by dark stippling in Fig. 2, has zonal speeds from 0.8 to $1.6 \mathrm{~m} \mathrm{~s}^{-1}$, and it is positioned within the thermocline (Fig. 5). For the $v$ component, stippling denotes northward flowing water. The instability waves are recognized as the large, regularly occurring, nearsurface confined oscillations that appear most prominently from August through December 1990.

The $u$-component isotachs are representative of the zonally oriented equatorial currents. Specifically, there is a highly variable, near-surface confined SEC overriding the EUC. Of the three latitudes sampled the EUC is maximum on and nearly symmetric about the equator, while the SEC is maximum to the north of the equator (as shown for the record-length mean profiles in Fig. 3). The primary variations in the EUC appear to be both annual and intraseasonal. Three periods of maximum EUC transport are observed: July-August 1990, De- 

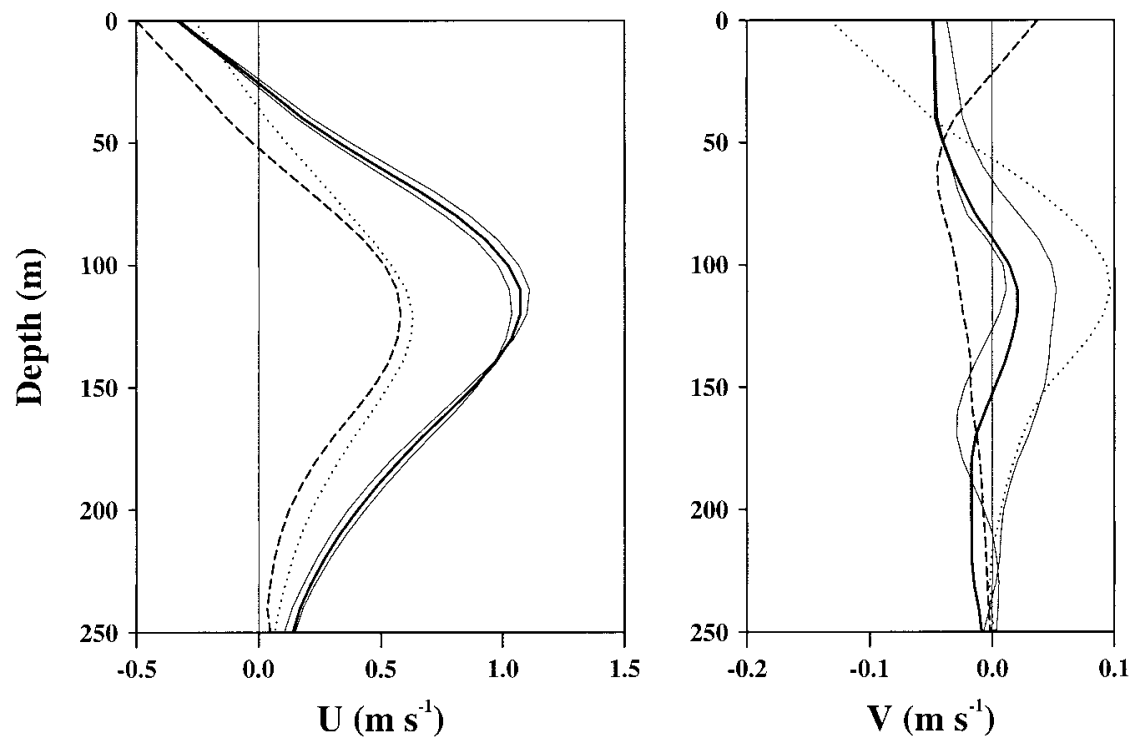

FIG. 3. Record-length mean profiles for the $u$ and $v$ components at the five mooring locations. The solid lines denote the three equator moorings (the thick one being $140^{\circ} \mathrm{W}$ ) and the dashed (dotted) lines denote the moorings north (south) of the equator.

cember 1990, and April-June 1991. During the summer and spring periods the EUC is shallow, as contrasted to the winter period when it is deeper. The shallow summer and spring maxima coincide with the annual cycle of the southeast trade winds. These winds relax over the eastern half of the equatorial Pacific in boreal spring, for example, see Meyers (1979) and Yang et al. (1997), causing a concomitant eastward acceleration of the nearsurface currents by the eastward-directed zonal pressure gradient force. The wintertime maximum occurs in response to westerly winds over the western equatorial Pacific. The SEC is most developed from August to December 1990, in between the first two EUC maxima, and again from February to April 1991, in between the second two EUC maxima. Other than these two periods, the SEC, as sampled by the TIWE equatorial array, is relatively weak, and westward flow is absent on the equator from April to June 1991.

Excepting the instability wave oscillations, the $v$ component is generally much smaller than $u$, this anisotropy being a consequence of vanishing Coriolis parameter on the equator. In 1990, the instability wave season lasted from August to December. It started with the westward acceleration of the SEC and ended with a wintertime Kelvin wave pulse whose leading edge eastward acceleration temporarily halted the SEC. The largest amplitudes for the instability wave's velocity oscillations occurred within the westward flowing SEC. These amplitudes decreased rapidly within the thermocline to relatively small values at and below the EUC core. The $v$-component oscillations were also largest on the equator, but they penetrated deeper with the SEC north of the equator. Descriptions of the instability wave's kinematics and energetics from the TIWE equatorial array are given by Qiao and Weisberg (1995) and Qiao and Weisberg (1998), respectively.

\section{c. Vertical velocity component estimation}

The smallness of $w$ obviates its direct measurement by the TIWE moored ADCPs. It is therefore estimated from the continuity equation:

$$
\partial u / \partial x+\partial v / \partial y=-\partial w / \partial z
$$

where $x, y$, and $z$ are positive to the east, north, and up, respectively. Center differences are used for the horizontal divergence, which is then integrated downward by a trapezoidal scheme in 10-m increments from an assumed rigid-lid surface to get $w$. For synoptic and longer timescales the approximation that $w=0$ at $z=$ 0 is correct by a factor of $10^{-2}$ relative to $w$ thus estimated.

The evolution of the terms in the the continuity equation: $\partial u / \partial x$ (the zonal divergence), $\partial v / \partial y$ (the meridional divergence), and $-\partial w / \partial z$ (the horizontal divergence) is shown in Fig. 4, where stippled regions denote divergence and clear regions denote convergence. The zonal divergence shows regular reversals near the surface during the instability wave season, and there is a general tendency for zonally divergent (convergent) flow above (below) the EUC core. In contrast with this, the meridional divergence shows a general tendency for divergent flow near the surface and convergent flow within the EUC. Summing these two components together to get the total horizontal divergence shows a tendency for divergent flow near the surface and convergent flow at depth. These tendencies are clearer upon record-length averaging as developed in section 4 . 


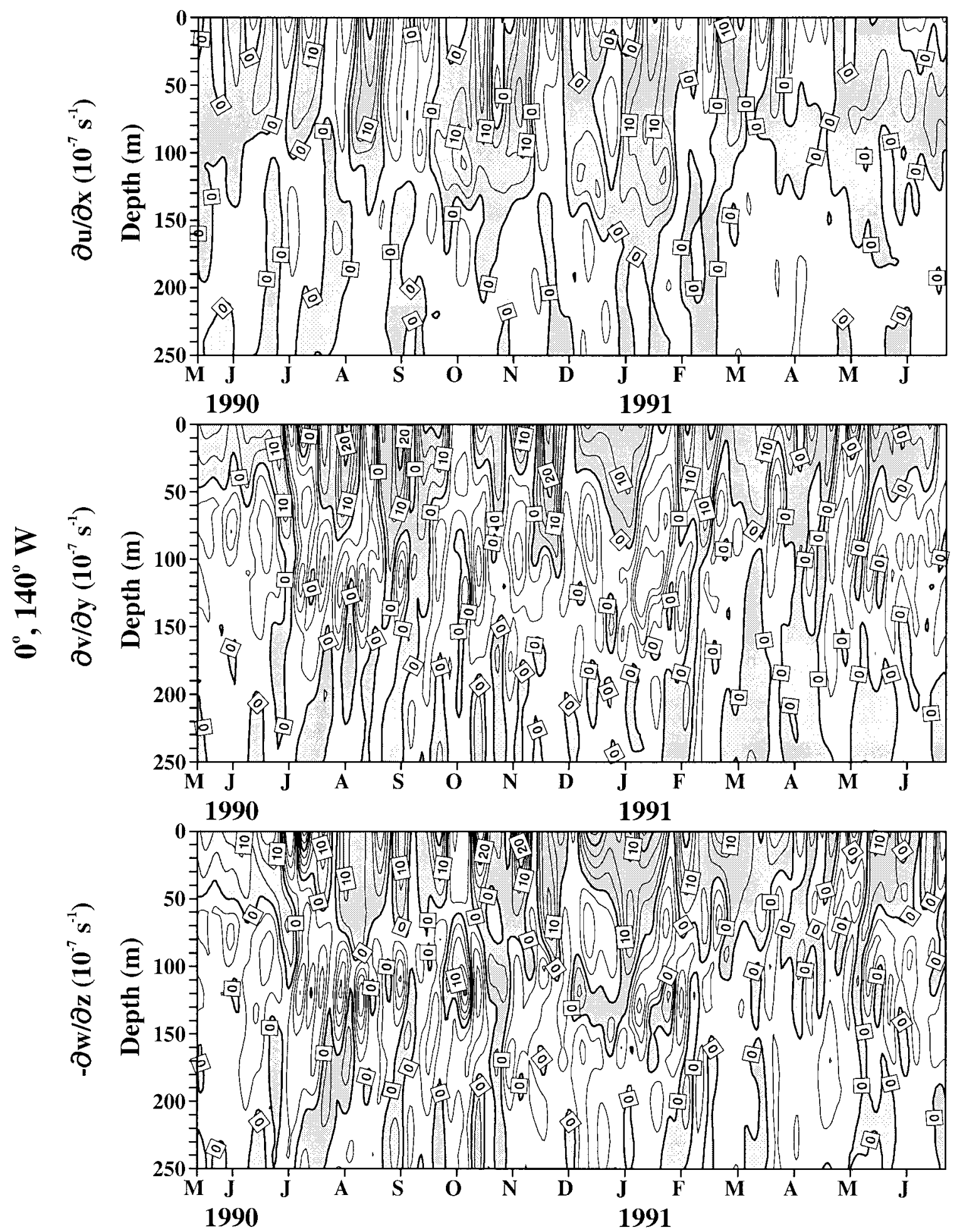

FIG. 4. From top to bottom: the zonal, meridional, and vertical divergences estimated by finite differences at $0^{\circ}, 140^{\circ} \mathrm{W}$. Stippled regions denote divergence, clear regions denote convergence, and all time series are low-pass filtered to remove oscillations at timescales shorter than 10 days. 
Vertically integrating the horizontal divergence results in the $w$ estimate as shown in Fig. 5, along with the surface zonal wind stress and the isotherm depths sampled at an adjacent TAO mooring. With the EUC core depth denoted by a bold line superimposed upon the isotherms, Fig. 5 shows that upwelling or downwelling may occur over the entire sampled water column (with speeds of order $10^{-4} \mathrm{~m} \mathrm{~s}^{-1}$ despite the tendency for upwelling (downwelling) to occur above (below) the EUC core. The latter feature is evident in Fig. 6 upon record-length averaging, where the relationship between $u, v$, and $w$ is shown. On average, $w$ is related to $u$, with upwelling observed in and above the EUC core and downwelling observed below. This finding is consistent with water converging onto the equator within the thermocline. Upon reaching the equator these convergent waters ascend (descend) above (below) the thermocline with the EUC within the thermocline being a dynamical consequence of this convergent flow.

\section{d. Estimation errors}

Estimation errors for $w$ derive in four general categories: random and systematic instrument errors and random and systematic geophysical sampling errors. These are discussed below in ascending order of importance.

The random instrument errors are associated with the ADCP's velocity calculation, which uses Doppler-shifted frequencies from range-gated, reflected sound returns that are sampled at the source transducer. Standard deviations determined by the manufacturer are a function of the sound returns per sampling interval (the ping rate) and the water volume sampled by each ping (the range gating). For the setup parameters employed, the standard deviation for each hourly sample is $0.012 \mathrm{~m} \mathrm{~s}^{-1}$. With all subsequent calculations being linear and with each sample independent, the standard deviation for the random instrument errors decreases with the square root of the number of samples averaged. For the low-frequency and record-length mean estimates presented, the random instrument errors and their effect upon $w$ are therefore negligible.

Random geophysical errors are more problematic, but nevertheless quantifiable. They follow from the time series variances due to the sampled geophysical processes, the effective bandwidth of these processes and hence the number of degrees of freedom, and the array geometry as applied to the vertically integrated divergence calculation. These factors are developed in the appendix where the standard deviations for the recordlength mean quantities, $\langle u\rangle,\langle v\rangle,\langle w\rangle$, and their derivatives, as presented in section 4 , are calculated. With regard to these random geophysical errors the findings presented herein are all well defined.

Systematic geophysical sampling errors are less quantifiable. They result from discrete sampling (in this case spatial) limitations for continuous geophysical process- es. This problem manifests as finite differencing errors, so the fundamental question is whether or not the array adequately resolves the principal physical processes that give rise to divergence. The processes of primary interest herein are the slowly varying seasonal circulation and the instability waves. The array design was based upon previously estimated spatial scales for the instability waves, and Qiao and Weisberg (1995) show that the array did resolve these features. The spatial scales for the slowly varying circulation are also resolved by the array. Estimated by either inertial or linear equatorial wave arguments, the meridional scales of the circulation are $(U / \beta)^{1 / 2}$ or $(C / \beta)^{1 / 2}$, respectively, where $U$ is the EUC core speed and $C$ is the equatorial wave speed. Thus, if the horizontal velocity components vary smoothly across the array (as shown for the recordlength mean $\langle u\rangle$ and $\langle v\rangle$ in Fig. 4) and the derivatives are continuous across the equator, then the finite-differencing errors, while not quantifiable, should not be overwhelming either. In particular, the finite differencing errors in $\partial\langle u\rangle / \partial x$ due to the meridional structure of $\langle u\rangle$ are shown to be small in the appendix. By virtue of a centered difference array, finite-differencing bias errors due to wave propagation are avoided, as was investigated using all possible differencing schemes available from the array. Supporting kinematical and dynamical arguments toward justifying these assertions are developed in sections 4 and 5 .

Systematic instrument errors, assuming correct beam geometry (incorrect geometry would translate into random errors since the instruments are free to rotate with the mooring), are those related to compass calibration. The manufacturer specifies a $\pm 2^{\circ}$ accuracy in the instrument's compass. Spinning the compass shows that this error is generally inhomogeneous with respect to coordinate direction. This inhomogeneity is actually good since mooring motion then tends to randomize the resulting error. The TIWE instrument compasses were checked to be within the manufacturer's specifications without constant offsets. Nevertheless, this is potentially the most serious source of error since, in view of large EUC speeds, a constant compass offset could largely bias the horizontal divergence by rotating the $u$ component onto the $v$ component. The appendix considers this effect by assuming constant and oppositely directed $2^{\circ}$ compass errors at the off-equator, TIW2 and TIW5 locations (effectively a $4^{\circ}$ compass error), and calculating what the vertically integrated effect of such erroneously large geostrophic convergence would be on the estimated downwelling below the EUC. The effect is the same order of magnitude as that estimated and it would account for about two-thirds of the value given (larger or smaller depending upon whether the compass errors point toward or away from the equator). On the other hand, if this were true, then dynamical inconsistencies (which are not observed) would occur as discussed in section 5 . 

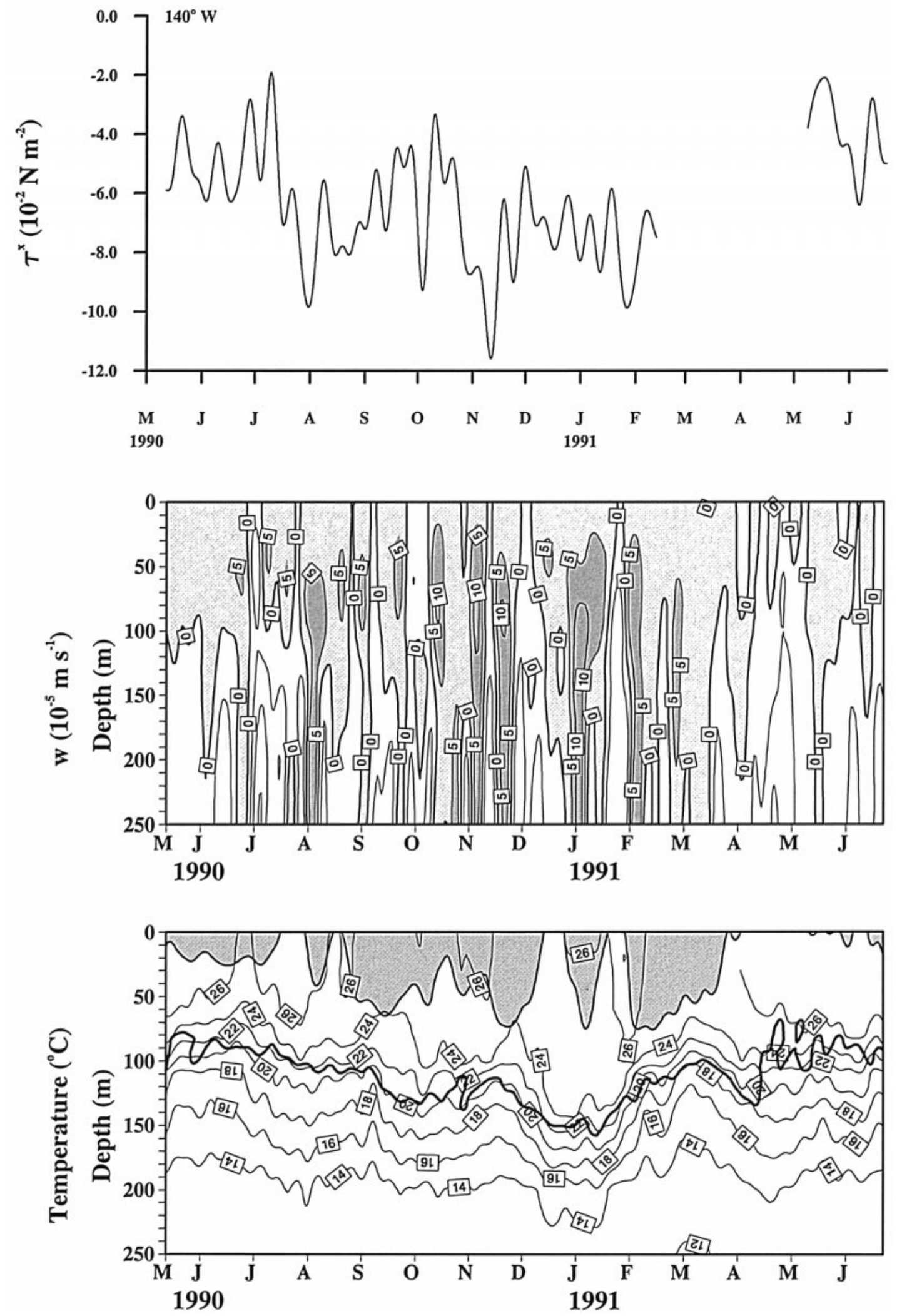

FIG. 5. The estimated $w$ (middle panel) as a function of time and depth at $0^{\circ}, 140^{\circ} \mathrm{W}$. The contour interval is $5 \times 10^{-5}$ $\mathrm{m} \mathrm{s}^{-1}$ and stippled (clear) regions denoting upwelling (downwelling). The bottom panel shows the isotherm depths as a function of time from the adjacent TAO mooring, with the EUC core depth indicated by a bold line and the region of westward flow near the surface indicated by stippling. The top panel is the zonal component of wind stress from the adjacent TAO mooring. 


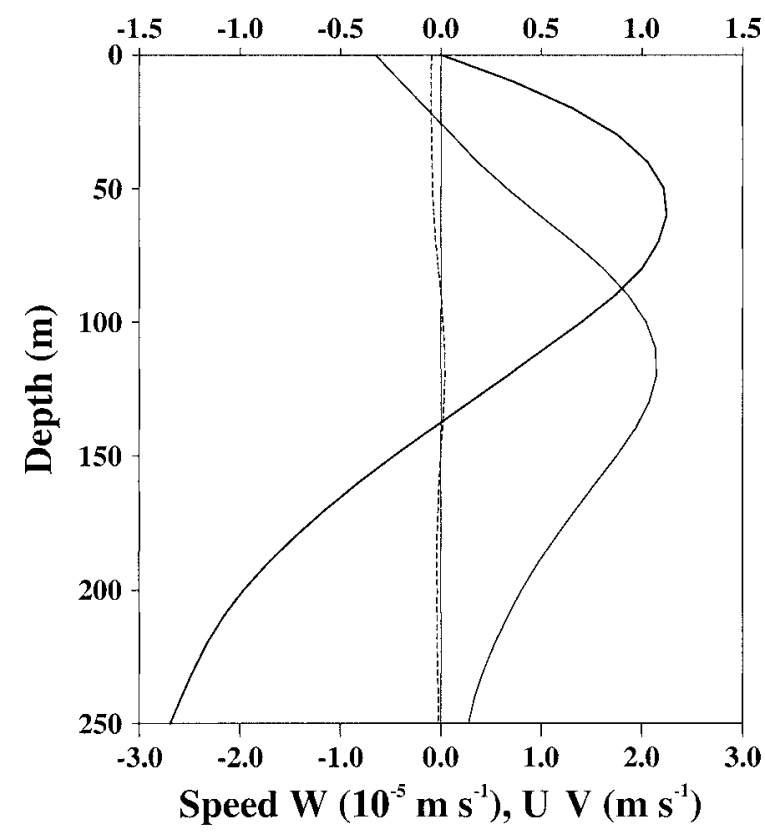

FIG. 6. Record-length mean profiles for $u$ (solid line), $v$ (dashed line), and $w$ (bold line). Note the change in scale (shown at the bottom) for $w$. Maximum upwelling of $2.3 \times 10^{-5} \mathrm{~m} \mathrm{~s}^{-1}$ occurs above the EUC core.

\section{Description of the mean velocity vector}

The velocity components averaged over the May 1990-June 1991 record length are again shown in Fig. 7, with the solid, dotted, and dashed lines denoting the means $\left(\left\langle v_{i}\right\rangle\right)$, the means \pm one standard deviation of the time series $\left(\left\langle v_{i}^{2}\right\rangle\right)^{1 / 2}$, and the means \pm one standard deviation of the means $\left(\left\langle v_{i}^{2}\right\rangle / n\right)^{1 / 2}$, respectively, where the number of degrees of freedom, $n$, are determined by integral timescale (see appendix). The equatorial current's anisotropy is clearly evident (in the low-frequen- cy, geostrophic limit, if the zonal pressure gradient (ZPG) is continuous across the equator, then $v=0$ on the equator by virtue of the Coriolis parameter changing sign across the equator). Within the near-surface region, a small but nonzero (in excess of one standard deviation of the mean) $\langle v\rangle$ may be attributed to ageostrophic wind effects consistent with a southward Sverdrup transport by negative wind stress curl over the eastern half of the basin. Below the near-surface region, $\langle v\rangle$ is zero within one standard deviation of the mean. The $u$ component on the equator shows a westward flowing SEC confined to the upper $25 \mathrm{~m}$. The mean position of the EUC core is at $110-\mathrm{m}$ depth ( \pm about $10 \mathrm{~m}$ to within one standard deviation of the mean) with a maximum speed of about $1.1 \mathrm{~m} \mathrm{~s}^{-1}$ ( \pm about $0.1 \mathrm{~m} \mathrm{~s}^{-1}$ to within one standard deviation of the mean). For both $\langle u\rangle$ and $\langle v\rangle$ the standard deviations are largest above the EUC core. The $w$ component shows maximum upwelling at $60 \mathrm{~m}$ (corresponding to the base of the mixed layer as evidenced in Figs. 5 or 10 ) of magnitude $2.3 \times 10^{-5} \mathrm{~m} \mathrm{~s}^{-1}$ ( \pm about 0.4 $\times 10^{-5} \mathrm{~m} \mathrm{~s}^{-1}$ to within one standard deviation of the mean) and a zero crossing at $140 \mathrm{~m}$ ( \pm about $10 \mathrm{~m}$ to within one standard deviation of the mean) just below the EUC core. While the standard deviation of $w$ is large, the standard deviation of $\langle w\rangle$ (a measure of geophysical random error) is small due to the large $n$ in the mean value estimation. As a consequence, both the magnitude of $\langle w\rangle$ and the depths of maximum value and zero crossing are well defined with respect to random geophysical error. Other errors, of course, may be larger. In summary, the vertical velocity component, on average, at this central equatorial Pacific location appears to be maximum at the base of the mixed layer with upwelling above the EUC core and downwelling (comparable in magnitude to the upwelling) beginning below the EUC core. Such large downwelling within the lower portion of the EUC is in contrast with several previous estimates reviewed in section 2 .
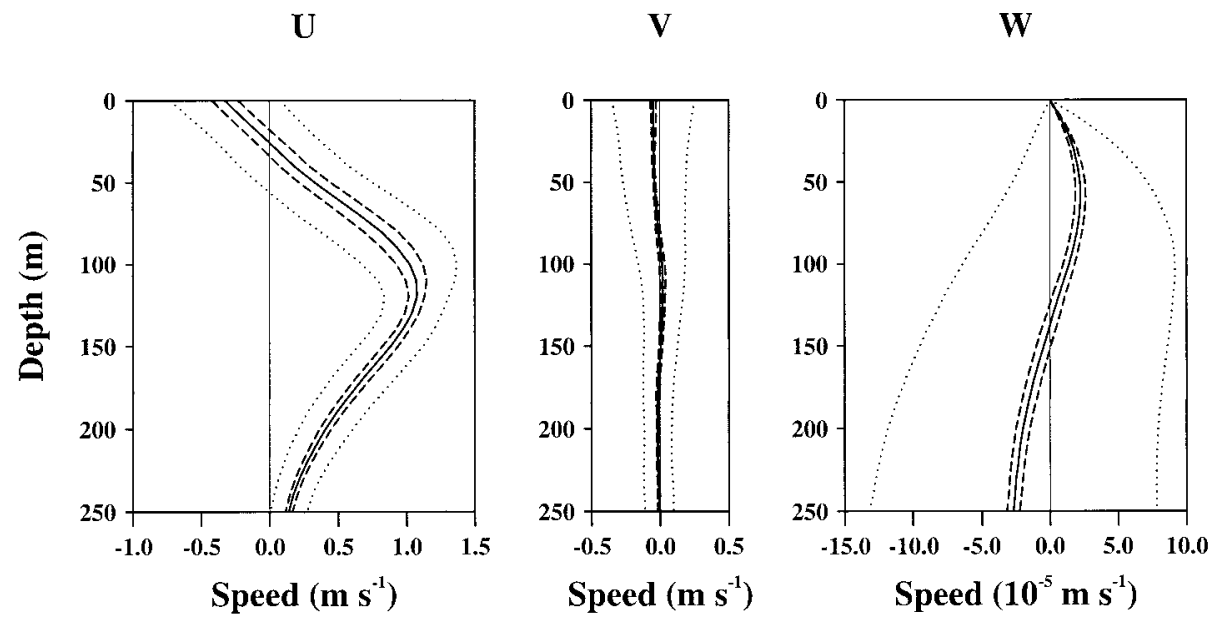

FIG. 7. Record-length mean profiles for $u, v$, and $w$ (solid lines), \pm the standard deviations of the time series from which they derive (dotted lines), and \pm the standard deviations of the means (dashed lines). 
$\mathrm{U}$ at $0^{\circ}, 138^{\circ} \mathrm{W}$ and $0^{\circ}, 142^{\circ} \mathrm{W}$

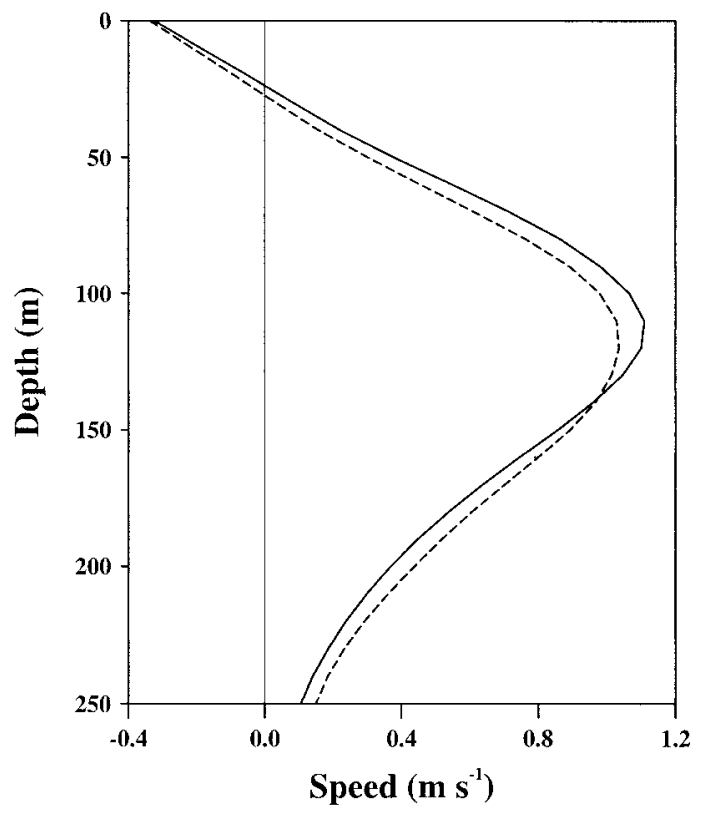

$\mathrm{V}$ at $1^{\circ} \mathrm{S}, 140^{\circ} \mathrm{W}$ and $1^{\circ} \mathrm{N}, 140^{\circ} \mathrm{W}$

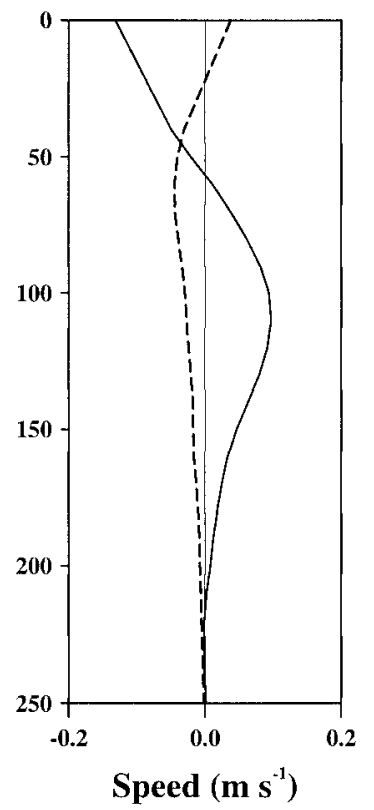

FIG. 8. The mean $u$-component profiles from which $\partial\langle u\rangle / \partial x$ is calculated, and the mean $v$ component profiles from which $\partial\langle v\rangle / \partial y$ is calculated.

With $w$ estimated via vertical integration of the continuity equation, the contribution by the zonal and meridional portions of the horizontal divergence is of interest. Figure 8 shows $\langle u\rangle$ and $\langle v\rangle$ as a function of depth at the along-equator and the off-equator locations from which the center differences for $\partial\langle u\rangle / \partial x$ and $\partial\langle v\rangle / \partial y$ at $0^{\circ}, 140^{\circ} \mathrm{W}$ are calculated. For $\langle u\rangle$ it is noted that the EUC accelerates (decelerates) downstream above (below) $140 \mathrm{~m}$, which coincides with the position at which $\langle w\rangle=0$. For $\langle v\rangle$ it is noted that meridionally divergent flow occurs near the surface, whereas meridionally convergent flow occurs within the region of the EUC, with maximum convergence occurring at the EUC core depth. It is further noted that both the flows away from the equator near the surface and toward the equator within the EUC are larger south of the equator than north of the equator. This small asymmetry is consistent with the zonal wind being larger on average south of the equator, producing asymmetries in the poleward Ekman and equatorward geostrophic transports. This is also consistent with the fact that the relatively high salinity within the EUC is of Southern Hemisphere origin. Referring back to Fig. 3, however, it is evident that the meridional divergence (near the surface) and convergence (near the EUC core) are still centered on the equator, on average.

While both components of divergences are important, the primary contributor to the horizontal divergence is the meridional divergence. Figure 9 shows the vertical distributions for $\partial\langle u\rangle / \partial x, \partial\langle v\rangle / \partial y$, and the negative of their sum, $\partial\langle w\rangle / \partial z$. The tendency is for $\partial\langle u\rangle / \partial x$ to oppose $\partial\langle v\rangle / \partial y$, leaving $\partial\langle w\rangle / \partial z$ as a residual (although above $40 \mathrm{~m}$ and below $140 \mathrm{~m}$ they are additive). A potential for finite differencing error derives from the meridional structure of $\langle u\rangle$ as seen in Fig 3. If $\partial\langle u\rangle / \partial x$ is similarly distributed, then it might be appropriate to scale the magnitude of $\partial\langle u\rangle / \partial x$ in the estimate of the $\partial\langle w\rangle / \partial z$ by a factor of about 0.8 . Doing this does not materially alter our findings, however, as shown in the appendix (Fig. A1), since $\partial\langle u\rangle / \partial x$ is of lesser importance than $\partial\langle v\rangle / \partial y$, so decreasing it by a small amount is of little consequence. Also, with the vertical average of $\partial\langle u\rangle / \partial x$ being divergent, a lessening of its effect tends to increase the magnitude of the downwelling below the EUC core, as opposed to decreasing it. For consistency with previous work we retain the unscaled formulations of Fig. 9. Note that the slopes of the divergence terms are all fairly constant above $60 \mathrm{~m}$, suggesting that the extrapolation procedure for the horizontal velocity components at $20 \mathrm{~m}$ and above is not adversely influencing the divergence calculation. The Fig. 9 vertical profiles are also smooth suggesting that the divergences, computed independently at each $10-\mathrm{m}$ interval, provide a consistent calculation of divergence within the standard errors of the mean value estimates. If the data themselves were "noisy" due to random instrument errors, such smooth profiles from independently sampled locations would not have been obtained. Last, along with the meridional convergence being maximum at the EUC core, it tends toward zero at the base of the EUC where the ZPG is small [Qiao and Weisberg (1997) suggest that the ZPG is zero there to within the reference level 

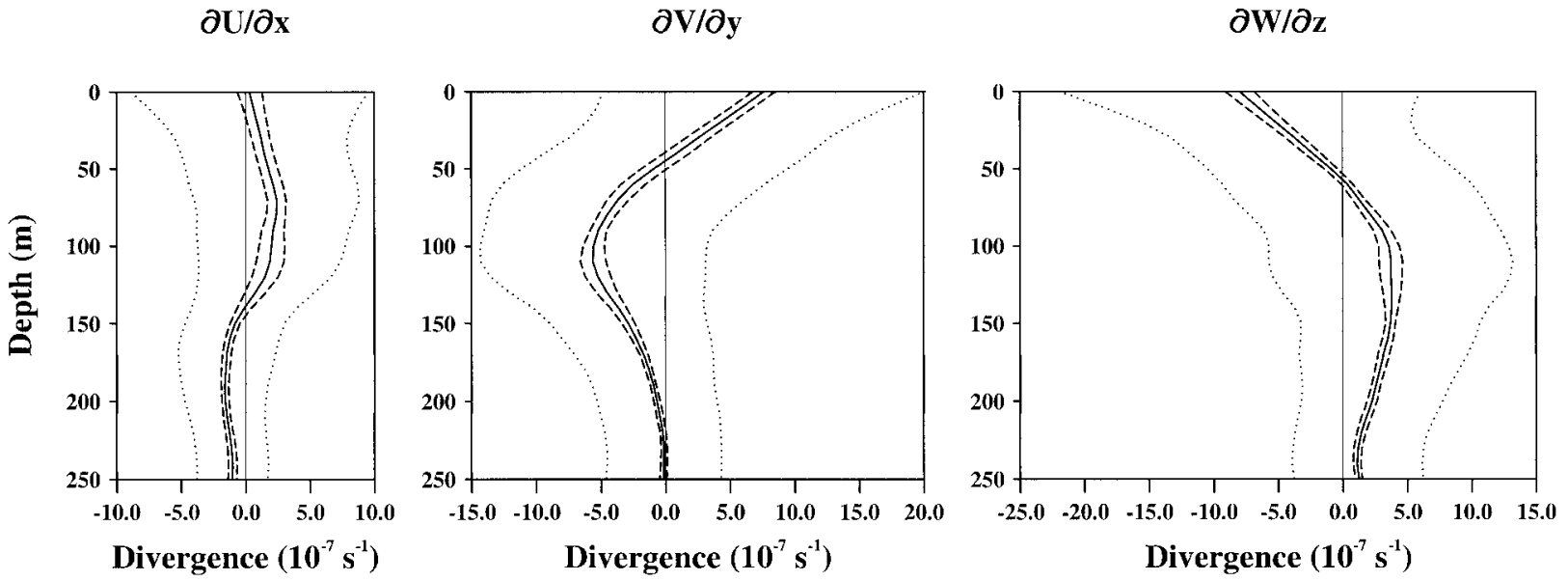

FIG. 9. The record-length mean zonal, meridional, and vertical divergence profiles (solid lines), \pm the standard deviations of the time series from which they derive (dotted lines), and \pm the standard deviations for the respective means (dashed lines).

error of about $0.2 \times 10^{-4} \mathrm{~N} \mathrm{~m}^{-3}$ ]. Dynamical consistency is therefore achieved by the horizontal divergence estimation.

In summary, both the zonal and the meridional divergences contribute to the total mean horizontal divergence. The zonal flow is divergent (convergent) at and above (below) the EUC core where the EUC accelerates (decelerates) downstream. The meridional flow is divergent within the near-surface region in accordance with poleward Ekman transport by a mean easterly wind stress and convergent within the EUC in accordance with a geostrophic transport by an eastward directed ZPG force. The depth at which the geostrophic convergence exceeds the Ekman divergence is approximately $50 \mathrm{~m}$. While the meridional convergence approaches zero at about $220 \mathrm{~m}$, the zonal convergence remains nonzero due to the downstream deceleration of the EUC. Consequently, the flow field remains horizontally convergent down to the $250-\mathrm{m}$ limit of our sampling, and for this reason the estimated downwelling magnitude continues to increase over the sampled domain. Omiting or scaling down the zonal portion of the divergence would increase the magnitude of the downwelling found below the EUC core.

The literature provides discussions on vertical velocity in terms of isopycnal and diapycnal portions (e.g., Gouriou and Reverdin 1992). The diapycnal portion arises as an advective imbalance in a material property's total derivative. If such imbalance exists, then the material property must either change locally or diffuse. While the TIWE array did not include concomitant temperature measurements, the TAO array did provide temperature data on scales sufficient for estimating a mean gradient. An advective temperature flux imbalance, and consequently a vertical distribution of implied turbulent heat transport, may therefore be estimated for the record-length mean. Using $\langle u\rangle$ and $\langle w\rangle$ from Fig. 7 and TAO temperature data from $0^{\circ}, 170^{\circ} \mathrm{W}$ and $0^{\circ}, 125^{\circ} \mathrm{W}$
Fig. 10 shows the vertical distribution in the equatorial zonal plane of the mean velocity vectors superimposed upon the mean isotherm slopes. With $\langle v\rangle=0$ on the equator, the degree of collinearity determines the advective temperature flux balance. The $21^{\circ} \mathrm{C}$ isotherm is the approximate point at which the isotherm and the velocity vector are collinear. Above (below) $21^{\circ} \mathrm{C}$ the velocity vectors are directed up (down) relative to the isotherms, implying a reversal in sign of the net advective temperature flux imbalance. The individual contributions of $\langle u\rangle \partial\langle T\rangle / \partial x$ and $\langle w\rangle \partial\langle T\rangle / \partial z$ (which tend to cancel within and above the EUC core) and their sum are shown in Fig. 11. The resulting advective temperature flux imbalance is relatively small, positive, and nearly uniform above the EUC core. It is both larger and negative below the EUC core. This imbalance requires a turbulent heat transport that may be parameterized by an entrainment (or diapycnal) velocity:

$$
\left\langle w_{e}\right\rangle=[\langle u\rangle \partial\langle T\rangle / \partial x+\langle w\rangle \partial\langle T\rangle / \partial z] / \partial\langle T\rangle / \partial z .
$$

A comparison between the estimated $\left\langle w_{e}\right\rangle$ and $\langle w\rangle$ is given in Fig. 12. Assuming that the entire advective temperature imbalance may be attributed to vertical eddy diffusion, the results suggest an upward (downward) turbulent heat flux above (below) the EUC core and a diapycnal vertical velocity with magnitude comparable to that of the kinematical vertical velocity. Of course these findings must be tempered by the fact that the velocity and the isotherm slopes were sampled over different scales.

\section{Supporting analyses}

Given an encouraging but inherently inconclusive error analysis, it is important to marshal ancillary information relative to the findings presented. Such evidence is drawn from both the time-dependent and the mean motions. For the time-dependent motions the following 


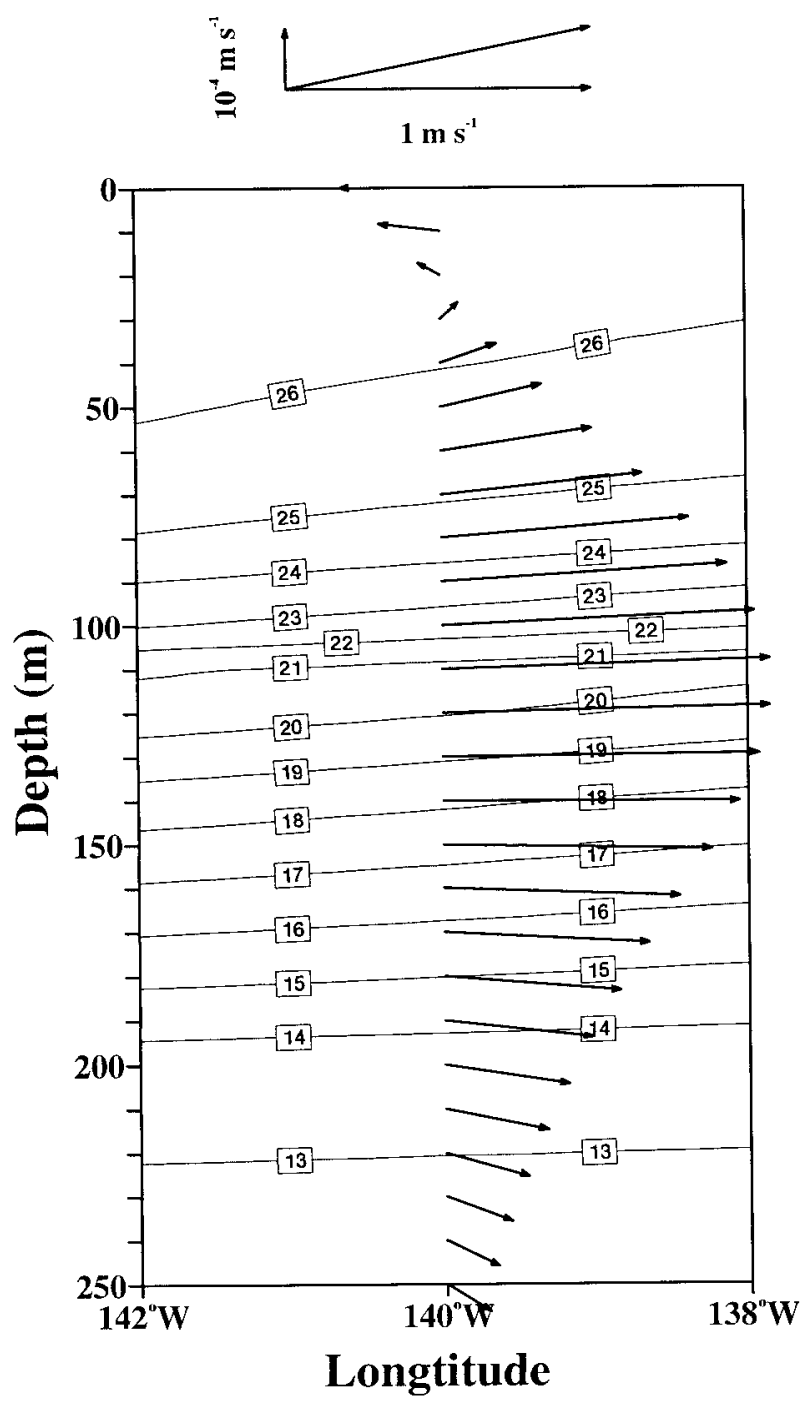

FIG. 10. Record-length mean velocity vectors superimposed upon mean isotherm slopes in the equatorial zonal plane at $0^{\circ}, 140^{\circ} \mathrm{W}$, where the isotherm slopes are from TAO array data at $0^{\circ}, 170^{\circ} \mathrm{W}$ and $0^{\circ}, 125^{\circ} \mathrm{W}$. Velocity (and isotherm slope) scale is shown at the top.

factors are examined: (a) the covariability between $\partial u / \partial x$ and $\partial v / \partial y$; (b) the velocity field kinematics; specifically, the relationship between $v$ on the equator and $w$ to the north and south of the equator; (c) the vorticity balance on the equator, both near the surface and at the EUC core; and (d) the relationship between $w$, the thermocline variations, and the local wind stress variations. For the mean motions, the dynamical balances within the EUC are considered. These are developed individually below.

\section{a. The covariability between $\partial u / \partial x$ and $\partial v / \partial y$}

Ocean planetary waves, such as the instability waves, should be only weakly divergent. What horizontal divergence exists should therefore be the residual between similar magnitude $\partial u / \partial x$ and $\partial v / \partial y$, each tending to can-
Sum, $<\mathbf{u}>\langle\partial \mathrm{T} / \partial \mathrm{x}\rangle,\langle\mathbf{w}\rangle\langle\partial \mathrm{T} / \partial \mathrm{z}\rangle$

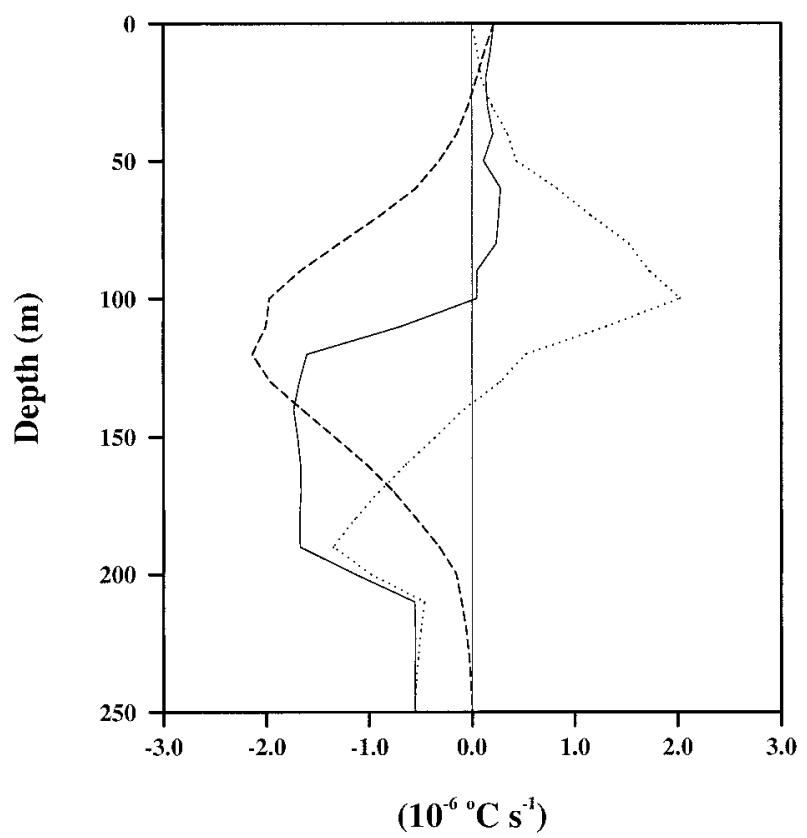

FIG. 11. Vertical profile of the record-length mean advective temperature flux imbalance (solid line) along with the individual contributions made by $\langle u\rangle \partial\langle T\rangle / \partial x$ (dashed line) and $\langle w\rangle \partial\langle T\rangle / \partial z$ dotted line).

cel the other with opposite sign. Inspection of Fig. 4 shows this to be the case within the surface layer during the instability wave season. When $\partial u / \partial x$ is convergent, $\partial v / \partial y$ is divergent and conversely.

\section{b. Velocity field kinematics}

Because of the $\beta$ effect, a near-surface water parcel transiting poleward from the equator is expected to sink as vortex filaments stretch. This behavior is observed in Fig. 13, wherein the $v$ component at 30-m depth on the equator during the instability wave season is superimposed upon the $w$ component at 60-m depth estimated between the equator and $1^{\circ} \mathrm{N}$ (using a forward difference for $\partial v / \partial y$ and a centered difference for $\partial u / \partial x$ ). The two time series covary out of phase, showing that when $v$ is northward, $w$ is downward, and conversely. The 60-m depth is chosen since that is where $w$ tends to be a maximum on average. During the instability wave season the time-dependent upwelling reaches speeds of $20 \mathrm{~m} \mathrm{day}^{-1}$, which is an order of magnitude larger than the average $w$ on the equator. These magnitudes are consistent with the numerical model results of Harrison (1996). A corollary to this finding is that $w$ south of the equator should covary opposite to $w$ north of the equator. This antisymmetric behavior is generally confirmed upon comparing $w$ as a function of time and depth at $0.5^{\circ} \mathrm{N}$ and $0.5^{\circ} \mathrm{S}$ in Fig. 14 (where forward and 


\section{$\mathrm{W}$ and $\mathrm{W}_{\mathrm{e}}$ at $0^{\circ}, 140^{\circ} \mathrm{W}$}

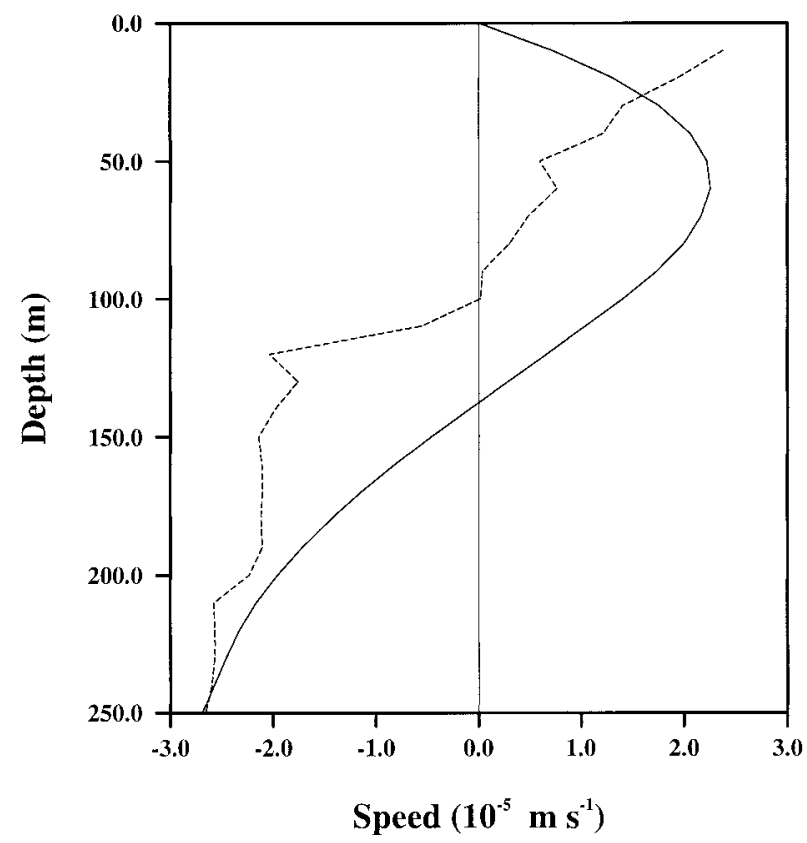

FIG. 12. The record-length mean profile of $\langle w\rangle$ (solid line) in comparison with the "diapycnal" or entrainment velocity $\left\langle w_{e}\right\rangle$ profile (dotted line) derived from the advective temperature flux imbalance and the mean vertical temperature gradient. Note that $\left\langle w_{e}\right\rangle$ is the difference between the estimated $\langle w\rangle$ and that required for flow along isotherms. backward differences are used for $\partial v / \partial y$ and a centered difference is retained for $\partial u / \partial x$ ). During the instability wave season, particularly August to December, very regular, well-defined features appear at $0.5^{\circ} \mathrm{N}$ versus less well-defined features at $0.5^{\circ} \mathrm{S}$. This observation matches the meridional inhomogeneity found for the instability waves in the numerical model simulation of Philander et al. (1986). Thus, for the instability waves a kinematical consistency occurs between water parcels crossing the equator and the $w$ component estimated to the north and south of the equator, and both the magnitude and the breakdown in symmetry agrees with numerical model results.

Symmetry properties at other timescales also apply. Equatorial wave theory (Matsuno 1966) includes wave modes for which $v$ is zero on the equator and $w$ is in phase across the equator. Spectral analysis (not shown) identifies another band of coherent vertical motions centered upon a 167-h periodicity that are in phase across the equator consistent with first meridional mode inertial-gravity waves.

\section{c. The vorticity balance on the equator}

The linearized vorticity balance on the equator depends upon the $\beta$ effect and the time-averaged curvature of the ambient flow field. Near the surface, the transient nature of the SEC and its meridional structure are such that the mean curvature is zero. The linearized vorticity balance near the surface is thus

$$
\partial \xi / \partial t+\beta v=0,
$$

where $\xi=\partial v / \partial x-\partial u / \partial y$ is the relative vorticity. Figure 15 shows the coherence squared, phase, and transfer

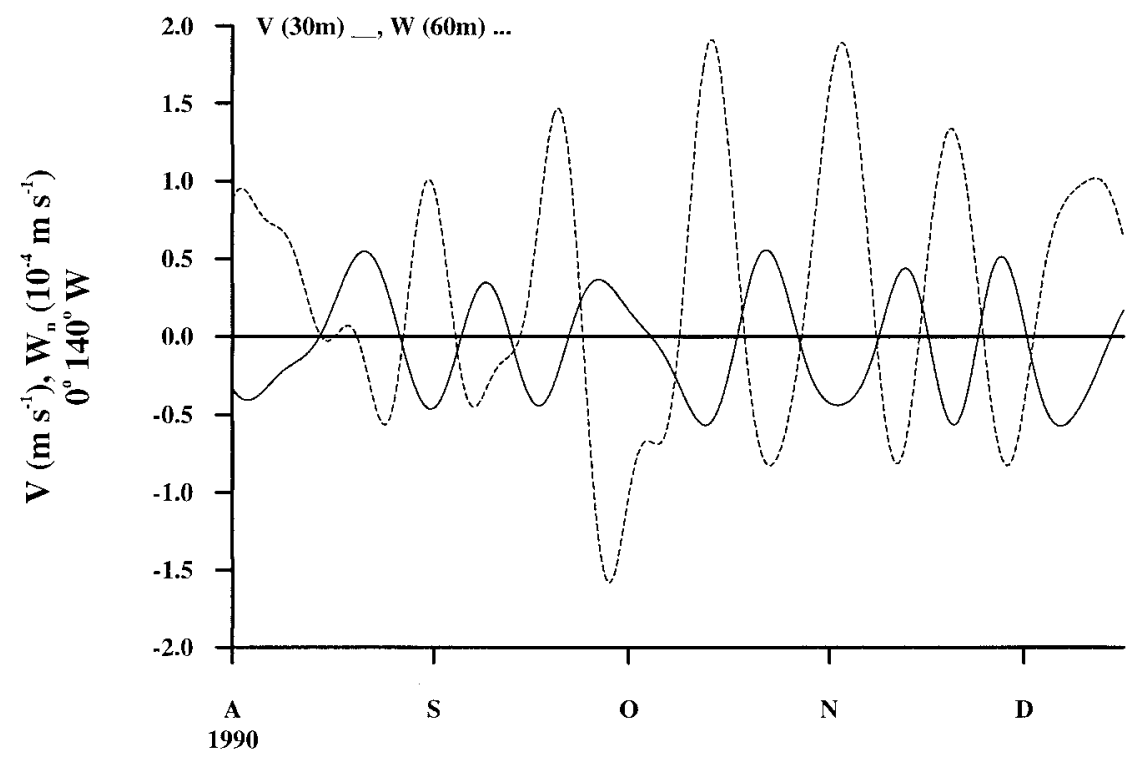

FIG. 13. The $v$ component on the equator at 30-m depth (solid line) superimposed upon the $w$ component estimated at $0.5^{\circ} \mathrm{N}$ at $60-\mathrm{m}$ depth (dashed line) during the instability wave season. 


\section{Speed $\mathrm{W}\left(10^{-5} \mathrm{~m} \mathrm{~s}^{-1}\right)$}
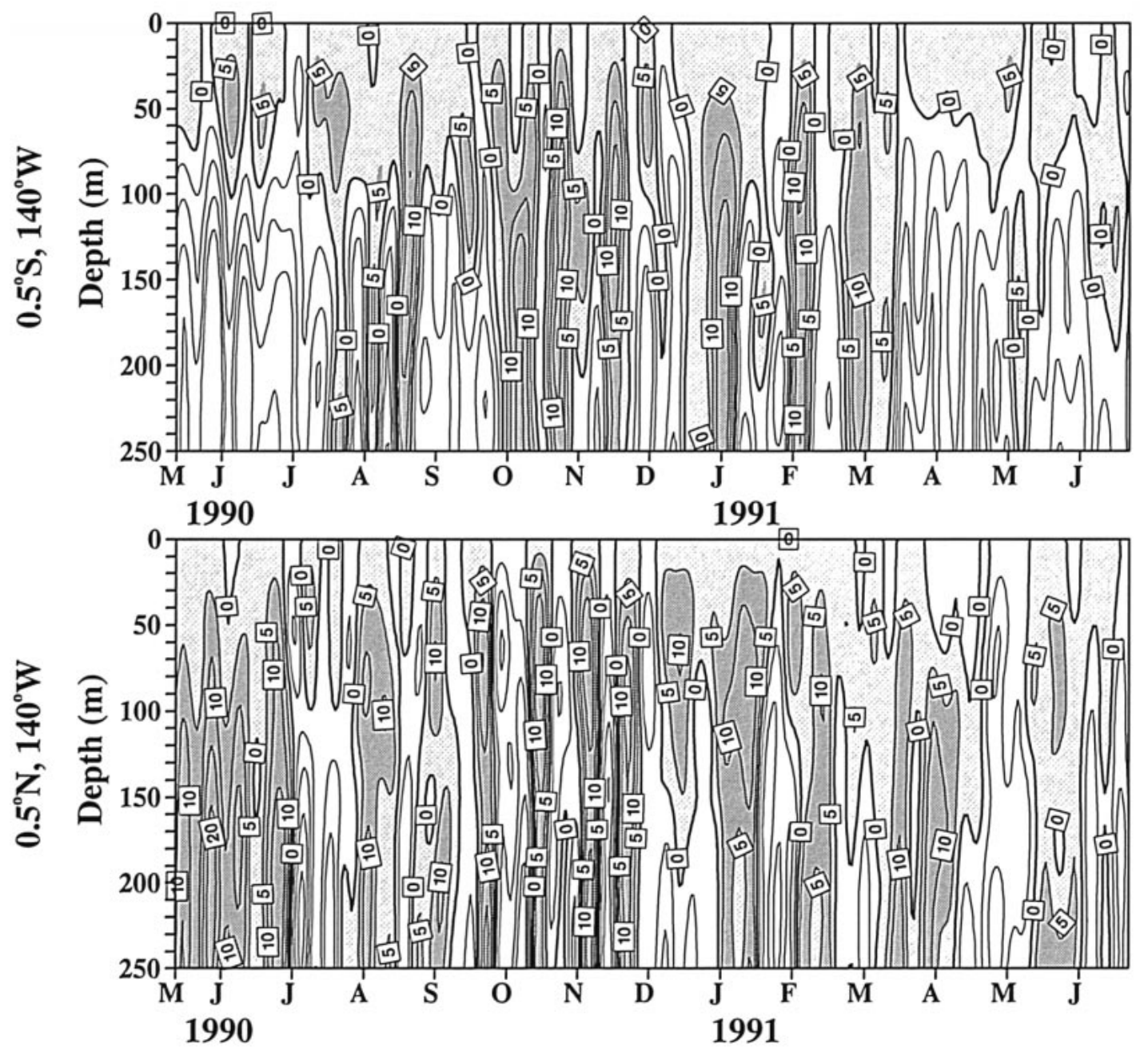

FIG. 14. Estimates of $w$ as a function of time and depth at $0.5^{\circ} \mathrm{N}$ lower panel and $0.5^{\circ} \mathrm{S}$ (upper panel) along $140^{\circ} \mathrm{W}$ (using forward and backward differences for $\partial v / \partial y$ and a centered difference for $\partial u / \partial x$ ). Stippling denotes upwelling.

function amplitude at 30-m depth (left panels) between $\beta^{-1} \partial \xi / \partial t$ (estimated by centered differences as in the divergence calculations) and $v$ on the equator. Within the instability wave band centered about 500-h periodicity, the coherence is high, the time series are out of phase, and the transfer function amplitude is close to 1.0. This agreement between theory and observations for the conservation of absolute vorticity using a finitedifference-derived $\xi$ suggests that the finite differencing errors are not overwhelming. Since the errors involved in the calculation of $\xi$ and $w$ are similar, this linearized vorticity balance provides implicit support for the $w$ estimation.

The linearized vorticity balance also holds at other depths. As the mean curvature of the background currents approaches $\beta$ in magnitude, curvature must also be taken into account. Thus, at the EUC core depth, where $\partial^{2} U / \partial y^{2}$ is large year-round, the linearized vorticity balance is

$$
\partial \xi / \partial t+\left(\beta-\partial^{2} U / \partial y^{2}\right) v=0 .
$$

Figure 15 also shows the coherence squared, phase, and transfer function amplitude between $\beta^{-1} \partial \xi / \partial t$ and $v$ at the EUC core depth (right panels). If the hypothesis is correct then these results should differ from those at 30-m depth in the transfer function amplitude by a factor of $\beta /\left[\beta-\left(\partial^{2} U / \partial y^{2}\right)\right]=0.34$ (with $\partial^{2} U / \partial y^{2}$ calculated by center difference between $1^{\circ} \mathrm{N}$ and $1^{\circ} \mathrm{S}$ ). This value agrees with the transfer function amplitude found at the center of the instability wave band. 
PERIOD-(HOURS)
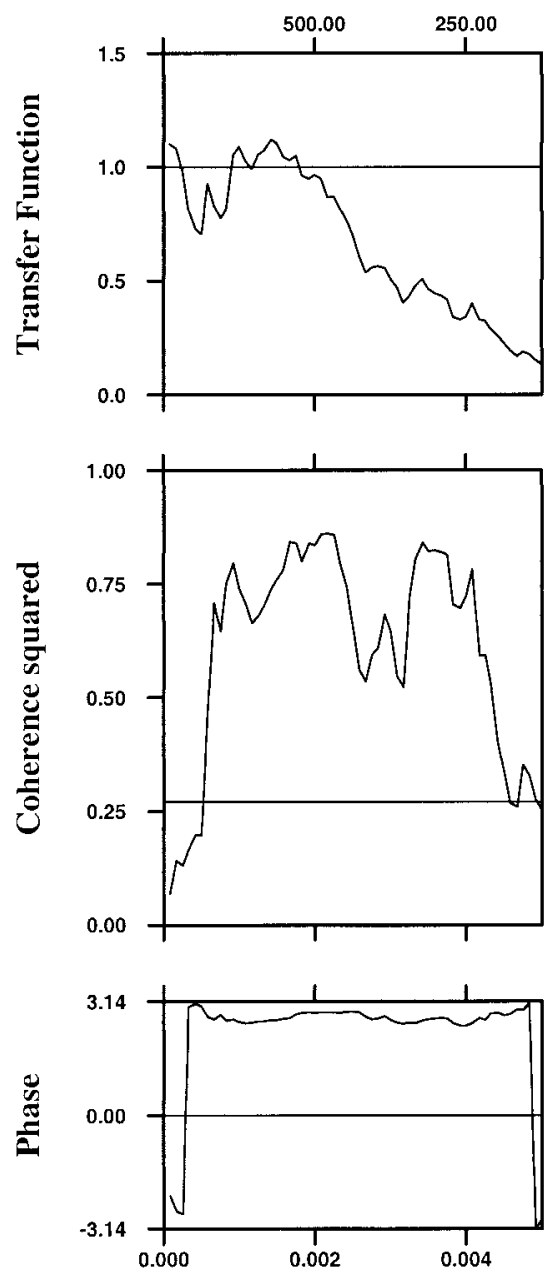

FREQUENCY-(C.P.H.)
PERIOD-(HOURS)
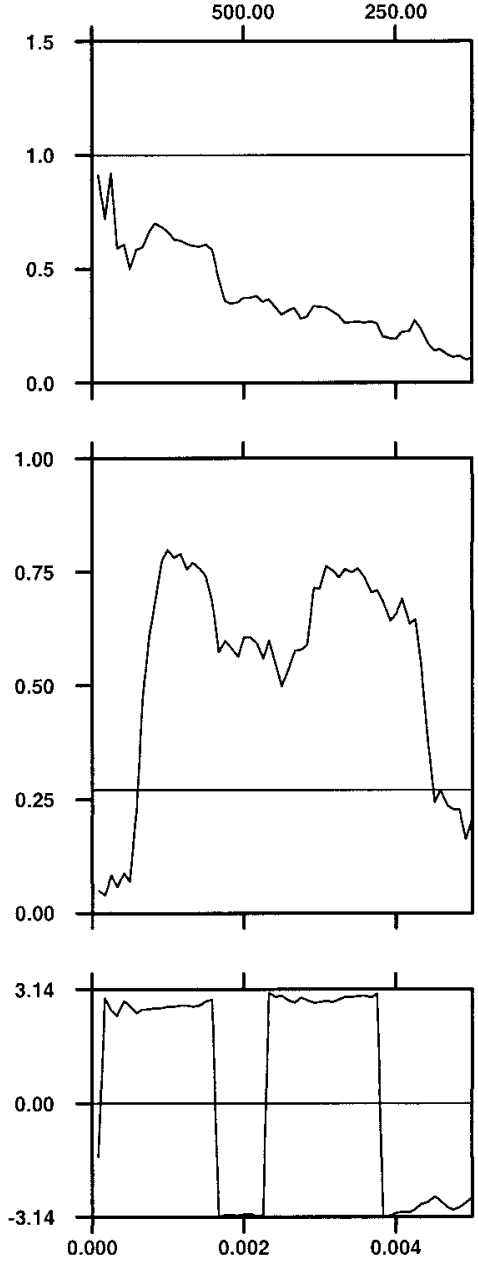

FREQUENCY-(C.P.H.)

FIG. 15. The coherence squared, phase, and transfer function amplitude between $(\partial \xi / \partial t) / \beta$ and $v$ on the equator at depths of $30 \mathrm{~m}$ (left panels) and $120 \mathrm{~m}$ (right panels). The bandwidth for the calculation is $0.0009 \mathrm{cph}$ resulting in about 17 degrees of freedom, and the associated $90 \%$ significance level on coherence squared as given by the horizontal line.

\section{$d$. The estimated $w$ relative to the thermocline and the local wind stress variations}

The fluctuations in $w$ have many sources, some local and some far field, as manifest through wave propagation. Along with the agreements found for the instability waves, qualitative agreements also exist between the estimated $w$ and the longer timescale variations in the thermocline. For example, the three major zonal current pulses in Fig. 5: July 1990, December 1990, and April 1991 all have downwelling associated with them and an attendant increase in thermocline depth. The estimated $w$ is largest when the local zonal winds are largest, and SST increases to its seasonal maximum to- ward the later part of the record when the zonal winds are relatively weak and $w$ is primarily downwelling.

\section{e. Velocity field kinematics in relation to the zonal momentum balance on the equator}

The fundamental theory for the existence of the equatorial undercurrent (e.g., Fofonoff and Montgomery 1955) suggests that the meridional convergence of water should be a maximum at the EUC core depth. If the EUC is accelerating and rising downstream with the thermocline then, on average, $\partial u / \partial x$ and $\partial v / \partial y$ should have the vertical distributions observed in Fig. 9. The sense of the meridional circulation and the vertical dis- 
tribution and magnitude of the mean $w$ above the EUC core agrees with the shipboard measurement-derived results of Knauss (1966). It is difficult to quantify what the meridional divergence should be at the surface on the equator since that would require knowledge of the vertical distribution of the Ekman divergence there. The values obtained are nevertheless in agreement with those of Hansen and Paul (1987), or Poulain (1993), from surface drifters when calculated over similar meridional separations. But even that comparison is difficult since the meridional shear (Fig. 9) varies linearly with depth from a zero crossing at $50 \mathrm{~m}$ to a maximum value at the surface. Since surface drifters have a 10-m drogue deployed on a 30-m tether, some of which break free, the depth at which surface drifters estimate divergence is unclear. Quantifying the meridional divergence at and below the EUC core depth is simpler, however, since there the observed covergence is controlled geostrophically by the ZPG. Assuming that the ZPG is symmetric about the equator, the meridional divergence due to geostrophic flow occurring $\Delta y$ degrees from the equator is given by

$$
\partial v / \partial y=-\left[\rho \beta \Delta y^{2}\right]^{-1} \partial P / \partial x .
$$

The vertical profile of the TIWE averaged ZPG on the equator, as given by Qiao and Weisberg (1997), has its maximum value at the surface, and it deceases monotonically to negligibly small values between $220 \mathrm{~m}$ and $250 \mathrm{~m}$ depths [supported by the Mangum and Hayes (1984) analysis of hydrographic data referenced to 1000 $\mathrm{db}$. Assuming that the ZPG decreases poleward from the equator proportional with the $u$ component (similar to an equatorial Kelvin wave) quantitative agreement is found between the geostrophic and the estimated $\partial v / \partial y$ (Fig. 9) from the EUC core depth to $250 \mathrm{~m}$. Not only is the magnitude at the core the same to within $10 \%$, but $\partial v / \partial y$ approaches zero between $220 \mathrm{~m}$ and $250 \mathrm{~m}$ along with the ZPG.

Finally, in the Qiao and Weisberg (1997) diagnosis of the zonal momentum balance, the vertical advection of momentum is as equally important as the other terms. When all terms are combined and vertically integrated, the record length averaged zonal wind stress quantitatively balances the ZPG in the vicinity of the EUC core. Also, when the vertical frictional stress profile is calculated as a residual between the material acceleration at each depth and the ZPG, it shows a zero crossing within $10 \mathrm{~m}$ of the EUC core, as expected. If the errors in $w$ were overwhelming, it is unlikely that these dynamical balances could have been realized.

\section{Discussion and summary}

The $\langle w\rangle$ profile implies an advective temperature flux imbalance (Figs. 10 and 11). Is the vertical distribution of this imbalance consistent with local heat fluxes, both at the surface and at depth? Consider first the positive region of the temperature flux imbalance above 100-m depth. Integrating vertically over this region and multiplying by $\rho C_{p}$ results in a net upward entrainment of relatively cold water from between the EUC core and the surface amounting to about $80 \mathrm{~W} \mathrm{~m}^{-2}$. This matches the annually averaged net surface heating in the vicinity of $0^{\circ}, 140^{\circ} \mathrm{W}$ to within the uncertainty given by the various surface flux estimates for the cold tongue region (e.g., Hastenrath and Lamb 1978; Esbensen and Kushnir 1981; Philander et al. 1987; Oberhuber 1988). Two statements follow: First, the agreement provides a thermodynamic consistency check on the near-surface estimate of upwelling. Second, if this is the way that the cold tongue is maintained, on annual average, then small interannual changes in the three-dimensional circulation associated with the EUC will result in interannual changes in the cold tongue temperature, unless accompanied by corresponding changes in the net surface heat flux.

The magnitude of the downward mixing of heat over the lower portion of the EUC appears to be much larger than the upward mixing of heat above the core. Integrating the temperature flux imbalance vertically between $100 \mathrm{~m}$ and $250 \mathrm{~m}$ depths results in about $680 \mathrm{~W}$ $\mathrm{m}^{-2}$. Is it physically reasonable for this amount of heat flux to be accounted for by vertical eddy diffusion? The question is approached in two ways. The first is to consider the eddy diffusivity at the 250-m depth necessary to accommodate such flux, and the second is to consider the eddy diffusive flux divergence between $130 \mathrm{~m}$ and $180 \mathrm{~m}$ where the advective flux imbalance is greatest. The formulations are similar: 1) $Q_{d}=\rho C_{p} K d T / d z$, where $K$ is the eddy coefficient and $Q_{d}$ (the flux at 250-m depth) is $680 \mathrm{~W} \mathrm{~m}^{-2}$, and 2) $d Q / d z=\rho C_{p} K d^{2} T / d z^{2}$, where $\left(\rho C_{p}\right)^{-1} d Q / d z$ (the imbalance from $130 \mathrm{~m}$ to 180 $\mathrm{m})$ is $1.7 \times 10^{-6}{ }^{\circ} \mathrm{C} \mathrm{s}^{-1}$. Estimating the appropriate temperature derivatives at $250 \mathrm{~m}$ and at $150 \mathrm{~m}$ (albeit from a poorly resolved mean vertical profile) gives similar values for $K$ of about $4 \times 10^{-3} \mathrm{~m}^{2} \mathrm{~s}^{-1}$. While this is large, it is within the range of microstructure measurements reported by Gregg (1987). Coincidentally, these heat flux estimates from beneath the EUC in the central Pacific agree with previous estimates made for the equatorial Atlantic by Weingartner and Weisberg (1991b) based on a more limited dataset. Such convergence below the EUC core and hence a downward advective temperature flux imbalance is also consistent with the observation of a thermostad region beneath the EUC and the steep downward bowing of dynamically passive tracers relative to dynamically active ones as noted in section 2. Using the same dataset, but with an independent analysis of the zonal momentum balance, versus the heat balance, Qiao and Weisberg (1997) arrived at a similarly large value for the eddy diffusion coefficient for momentum. For both quantities, heat and momentum, the requirement for large vertical mixing follows directly from the downwelling estimated over the lower portion of the EUC. A dynamical basis for the connection between downwelling and mixing is giv- 
en by Charney (1960) and Charney and Spiegel (1971). Robinson (1966) found best agreement between theory and observation for a vertical eddy diffusivity that varied in qualitative agreement with that found here, and Philander (1973) also concluded that downwelling occurs below the EUC core.

The entrainment velocity estimated from the advective temperature flux imbalance is found to increase linearly between the EUC core and the near surface. Since the mixed layer is about $60 \mathrm{~m}$ deep, it may be physically more appropriate to terminate the entrainment velocity calculation at $60 \mathrm{~m}$ where its magnitude is about $0.8 \times 10^{-5} \mathrm{~m} \mathrm{~s}^{-1}$. Improved estimates of material property fluxes and derived quantities such as entrainment velocity will require improved measurements of the material property gradients.

The primary difference between our estimates of $w$ and those obtained by Bryden and Brady (1985), or others using the continuity equation with sparsely sampled data (section 2), is in the vertical profile. Our results show upwelling within and above the EUC core and downwelling of equal magnitude below, as opposed to upwelling across almost the entire EUC. It is this difference in vertical velocity below the core that has important implications both for dynamical and material property balances. Numerical models, particularly those employing bulk Richardson-number-dependent vertical eddy diffusion coefficients, also tend to show upwelling across the entire EUC, in contrast to our findings. This may be attributed to the fact that vertical diffusion below the EUC core in such models is very small. With small dissipation and no opposing pressure gradient force, fluid cannot downwell within the EUC because there is no means of decelerating the fluid between the EUC core and the slower region below (Qiao and Weisberg 1997). In other words the fully three-dimensional circulation associated with the EUC is critically dependent upon the dissipation that occurs within it. Since this circulation determines the equatorial ocean cold tongues, it follows that an unequivocal determination of the fully three-dimensional circulation structure associated with the EUC is a necessary step toward improving ocean models of the Tropics, particularly those coupled with atmosphere models. Only through an independent dataset is it possible to test whether a coupled oceanatmosphere model simulates SST for the correct reason.

In summary, the TIWE equatorial array provides estimates of the vertical velocity profile within the upper $250 \mathrm{~m}$ in the central Pacific at $0^{\circ}, 140^{\circ} \mathrm{W}$. The array appears to resolve the primary producers of upper-ocean divergence on seasonal and synoptic scales, thereby providing physically plausible estimates of volume flux. While plausible, important discrepancies exist that require further testing, particularly the downwelling below the EUC core and the implied large mixing rates. The TIWE array lacked adequate temperature and salinity measurements for properly assessing heat and other material property budgets, and data from the TAO array are sampled too coarsely for process experimentation. Required for improved understandings of the equatorial cold tongues and the transport pathways that link the Tropics with the equator is a process-oriented dataset sufficient to determine the relative importances of the equatorial ocean circulation and the net surface heat and buoyancy fluxes in determining both SST and the downward mixing of material properties.

Acknowledgments. Support was provided by the Ocean Sciences Division, National Science Foundation, Grant Numbers OCE-8813378 and OCE-9302811. Messrs. R. Cole and J. Donovan assisted with the instrumentation, field deployments, and data analyses. Dr. C. Wang provided many helpful discussions. The officers and crew of the R/V Wecoma and the R/V Alpha Helix made the sea-going operations safe, successful, and pleasurable. M. McPhaden and L. Mangum (NOAA/PMEL) kindly provided the TAO array data used in this study.

\section{APPENDIX}

\section{Error Analysis}

\section{a. Random geophysical errors}

The procedure for estimating the random geophysical errors for the TIWE horizontal velocity component mean values is the same as given in Qiao and Weisberg (1997). It is assumed that these measured quantities derive from stationary, Gaussian distributed, random variables satisfying the ergodic hypothesis. The divergence constituents, $\partial\langle u\rangle / \partial x, \partial\langle v\rangle / \partial y, \partial\langle w\rangle / \partial z$, and $w$ are estimated by linear operations upon $u$ and $v$ so their distributions are also Gaussian. Thus, their variance estimates all follow from

$$
\operatorname{var}\{X\}=\tau_{0} T^{-1} C_{x}(0),
$$

where $\operatorname{var}\{\}$ is the variance operator, $x$ is a stationary random variable, $X$ is its record length $(T)$ averaged mean value estimate, $C_{x}(0)$ is its autocovariance at zero lag, and $\tau_{0}$ is its integral timescale (e.g., Tennekes and Lumley 1972) given by

$$
\tau_{0}=\frac{\int_{-T}^{T} C_{x}(\tau) d \tau}{C_{x}(0)} .
$$

Standard deviations are calculated as the positive square root of the variances, and the equivalent degrees of freedom, in analogy to band-limited white noise, is $N=$ $T \tau_{0}^{-1}$. With the exception of the $u$ component in the vicinity of the EUC core, for which $N$ is as small as 15, all other time series, including the divergence constituents and $w$ have values of $N$ greater than 30 . 
$\partial \mathbf{W} / \partial \mathbf{z}$

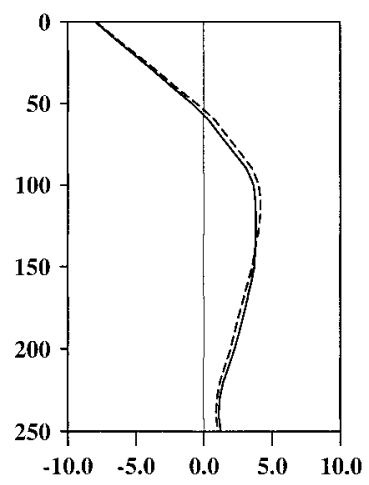

Divergence $\left(10^{-7} s^{-1}\right)$
W

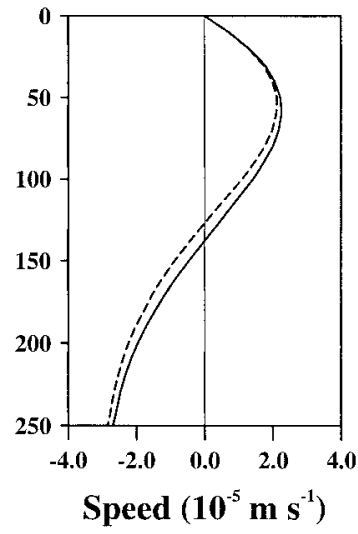

FIG. A1. Comparisons between horizontal divergence and vertical velocity profiles when calculated using unscaled (as in the text) or scaled values of $\partial\langle u\rangle / \partial x$. The solid lines are for the centered difference values of $\partial\langle u\rangle / \partial x$ estimated on the equator and the dashed lines are for 0.8 times $\partial\langle u\rangle / \partial x$ where the factor of 0.8 approximates the average of $\langle u\rangle$ between the equator and $1^{\circ} \mathrm{N}$ and $\mathrm{S}$.

\section{b. Systematic error in $\partial\langle u\rangle / \partial x$}

Figure A2 compares vertical profiles for the record length averaged horizontal divergence and vertical velocity calculated using either $\partial\langle u\rangle / \partial x$ evaluated on the equator (solid line) or 0.8 times $\partial\langle u\rangle / \partial x$ (dashed line). The rationale for scaling down the centered difference $\partial\langle u\rangle / \partial x$ follows from the symmetry of $\langle u\rangle$ about the equator (Fig. 3). The factor of 0.8 approximates the average of $\langle u\rangle$ between the equator and $1^{\circ} \mathrm{N}$ and S. Either formulation gives nearly the same result since $\partial\langle u\rangle / \partial x$ plays a secondary role to $\partial\langle v\rangle / \partial y$ in the horizontal divergence. Small changes in $\partial\langle u\rangle / \partial x$ are therefore inconsequential. For consistency with other w determinations we use the unscaled formulation in the text.

\section{c. Systematic compass calibration errors}

Let $(u, v)$ be the horizontal velocity components in the conventional $(x, y)$ coordinate system directed positive to the east and north, respectively. In the event of a constant compass offset by $\alpha$ degrees, the ADCP will yield velocity components $\left(u^{\prime}, v^{\prime}\right)$ in the rotated coordinate system $\left(x^{\prime}, y^{\prime}\right)$. For an anticlockwise rotation the coordinate transformation is

$$
\begin{aligned}
& u^{\prime}=u \cos \alpha-v \sin \alpha, \\
& v^{\prime}=u \sin \alpha+v \cos \alpha .
\end{aligned}
$$

Consider the case of a $2^{\circ}$ compass offset whereby $\cos \alpha$ $=1$ and $|\sin \alpha|=0.035$. Thus, $u^{\prime}=u$ and $v^{\prime}=-u$ $\sin \alpha+v$. The $u$ component is unaffected, whereas the $v$ component may be affected in the event of large $u$. Since the EUC presents such a scenario it is important to calculate what this potential source of error might be for the calculation of the meridional divergence and hence $w$.

Consider a worst case for which there are oppositely directed compass offsets to the north and south of the equator on the TIW5 and TIW2 moorings. This would effectively result in an additive $4^{\circ}$ error on meridional divergence. The maximum bias will ocur at the EUC core where $u$ is largest. For $\partial\langle v\rangle / \partial y$ and $\langle w\rangle$ the errors are $\left[\left|u_{n}^{\prime}\right|+\left|u_{s}^{\prime}\right|\right](2 \Delta y)^{-1} \sin 2^{\circ}$ and $\left\{\left[\left|u_{n}^{\prime}\right|+\left|u_{s}^{\prime}\right|\right](2 \Delta y)^{-1}\right.$ $\left.\left.\sin 2^{\circ}\right]\right\} d z$, respectively. These worst case errors are shown in Fig. A1. The reversal in sign with depth of the meridional divergence error results in a partial cancellation of the $w$ error upon vertical integration. Nevertheless, at 250-m depth some two-thirds of the downwelling could be attributed to such error (although we note that, if the compass errors pointed the opposite direction, then the downwelling would be substantially higher). As noted, the compasses were checked and such constant offsets were not found. Such error would also

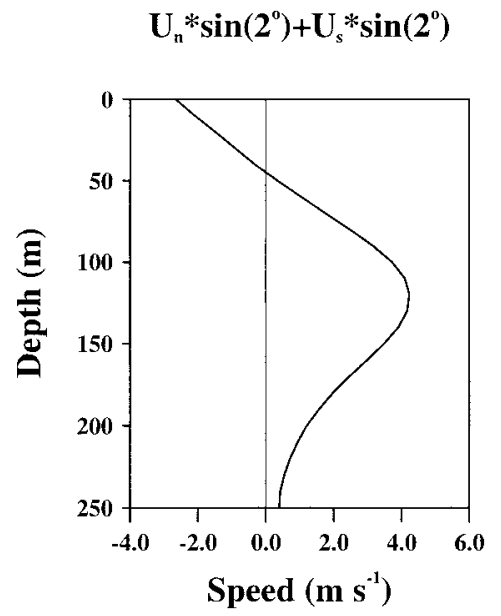

Error in $\partial \mathrm{V} / \partial \mathbf{y}$

Error in W
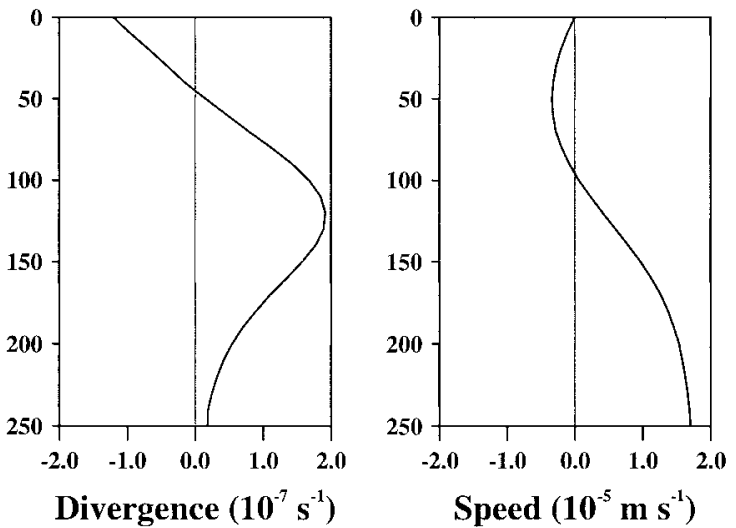

FIG. A2. Error profiles for $\langle v\rangle, \partial\langle v\rangle / \partial y$, and $\langle w\rangle$ assuming systematic and oppositely directed $2^{\circ}$ compass errors on each of the two off-equator moorings. 
cause an inconsistency with the ZPG calculated meridional divergence at the EUC core, which is not observed.

\section{REFERENCES}

Bjerknes, J., 1966: A possible response of the atmospheric Hadley circulation to equatorial anomalies of ocean temperature. Tellus, 18, 820-829.

Broecker, W., T.-H. Peng, and M. Stuiver, 1978: An estimate of the upwelling rate in the equatorial Atlantic based on the distribution of bomb radiocarbon. J. Geophys. Res., 83, 6179-6186.

Bryden, H. L., and E. C. Brady, 1985: diagnostic model of threedimensional circulation in the upper equatorial Pacific Ocean. $J$. Phys. Oceanogr., 5, 1255-1273.

Charney, J. G., 1960: Non-linear theory of a wind-driven homogeneous layer near the equator. Deep-Sea Res., 6, 303-310.

_ rents in homogeneous oceans. J. Phys. Oceanogr., 1, 149-160.

Cromwell, T., 1953: Circulation in a meridional plane in the central equatorial Pacific. J. Mar. Res., 12, 196-213.

Defant, A., 1981: The Troposphere. W. J. Emery, Transl. Ed., Amerind, $113 \mathrm{pp}$.

Esbensen, S. K., and V. Kushnir, 1981: The heat budget of the global ocean: An atlas based on estimates from surface marine observations. Climate Research Institute Rep. 29, Oregon State University, Corvallis, OR, $27 \mathrm{pp}$ and 188 figures.

Fine, R. A., W. H. Peterson, C. G. H. Rooth, and H. G. Ostlund, 1983: Cross equatorial tracer transport in the upper waters of the Pacific Ocean. J. Geophys. Res., 88, 763-769.

Fofonoff, N. P., and R. B. Montgomery, 1955: The Equatorial Undercurrent in the light of the vorticity equation. Tellus, 7, 518521.

Gouriou, Y., and G. Reverdin, 1992: Isopycnal and diapycnal circulation of the upper equatorial Atlantic Ocean in 1983-1984. J. Geophys. Res., 97, 3543-3572.

Gregg, M. C., 1987: Diapycnal mixing in the thermocline: A review. J. Geophys. Res., 92, 5249-5286.

Halpern, D., and P. H. Freitag, 1987: Vertical motion in the upper ocean of the equatorial eastern Pacific. Oceanol. Acta., Proc. Int. Symp. on Equatorial Vertical Motion, SP, 19-26.

— , and R. H. Weisberg, 1989: Upper ocean thermal and flow fields at $0^{\circ}, 28^{\circ} \mathrm{W}$ (Atlantic) and $0^{\circ}, 140^{\circ} \mathrm{W}$ (Pacific) during 1983 1985. Deep-Sea Res., 36, 407-418.

- R. A. Knox, D. S. Luther, and S. G. H. Philander, 1989: Estimates of equatorial upwelling between $140^{\circ} \mathrm{W}$ and $110^{\circ} \mathrm{W}$ during 1984. J. Geophys. Res., 94, 8018-8020.

Hansen, D., and C. Paul, 1984: Genesis and effects of long waves in the equatorial Pacific. J. Geophys. Res., 89, $10431-10440$. , and - , 1987: Vertical motion in the eastern equatorial Pacific inferred from drifting buoys. Oceanol. Acta., Proc. Int. Symp. on Equatorial Vertical Motion, SP, 27-32.

Harrison, D. E., 1996: Vertical velocity in the central tropical Pacific: a circulation model perspective for JGOFS. Deep-Sea Res. II, 43, 687-705.

Hastenrath, S., and P. J. Lamb, 1978: Heat Budget Atlas of the Tropical Atlantic and Eastern Pacific Oceans. University of Wisconsin Press, $104 \mathrm{pp}$.

Johnson, E. S., and D. S. Luther, 1994: Mean zonal momentum balance in the upper and central equatorial Pacific Ocean. J. Geophys. Res., 99, 7689-7705.

Kessler, W. S., M. J. McPhaden, and K. M. Weickmann, 1995: Forcing of intraseasonal Kelvin waves in the equatorial Pacific. J. Geophys. Res., 100, 10 613-10 632.

Knauss, J. A., 1966: Further measurements and observations of the Cromwell Current. J. Mar. Res., 24, 205-240.

Knox, R. A., and D. Halpern, 1982: Long range Kelvin wave propagation of transport variations in Pacific Ocean equatorial currents. J. Mar. Res., 40 (Suppl), 329-339.

Lau, K. M., and P. H. Chan, 1985: Aspects of the 40-50 day oscil- lation during northern winter as inferred from outgoing long wave radiation. Mon. Wea. Rev., 113, 1889-1909.

Levitus, S., 1988: Ekman volume fluxes for the World Ocean and individual ocean basins. J. Phys. Oceanogr., 18, 271-279.

Mangum, L. J., and S. P. Hayes, 1984: The vertical structure of the zonal pressure gradient in the eastern Equatorial Pacific. J. Geophys. Res., 89, $10441-10450$.

Matsuno, T., 1966: Quasi-geostrophic motions in the equatorial area. J. Meteor. Soc. Japan, 2, 25-43.

McPhaden, M. J., and B. A. Taft, 1988: Dynamics of seasonal and intraseasonal variability in the eastern equatorial Pacific. J. Phys. Oceanogr., 18, 1713-1732.

Meyers, G., 1979: Annual variation in the slope of the $14^{\circ} \mathrm{C}$ isotherm along the equator in the Pacific Ocean. J. Phys. Oceanogr., 9, 885-891.

Mitchell, T. P., and J. M. Wallace, 1992: The annual cycle in equatorial convection and sea surface temperature. J. Climate, 5, 11401156.

Oberhuber, J. M., 1988: An Atlas Based an the 'COADS' Data Set: The Budgets of Heat, Buoyancy, and Turbulent Kinetic Energy at the Surface of the Global Ocean. Max-Planck Institut für Meteorologie Rep. 15, Max-Planck-Institut für Meteorologie, Hamburg, Germany, 199 pp.

Philander, S. G. H., 1973: The equatorial thermocline. Deep-Sea Res., 20, 69-86.

1990: El Niño, La Niña, and the Southern Oscillation. Academic Press, 289 pp.

, W. J. Hurlin, and R. C. Pacanowski, 1986: Properties of long equatorial waves in models of the seasonal cycle in the tropical Atlantic and Pacific Oceans. J. Geophys. Res., 91, $14207-$ 14211.

- - , and A. D. Siegel, 1987: Simulation of the seasonal cycle of the tropical Pacific Ocean. J. Phys. Oceanogr., 17, 19862002.

Poulain, P. M., 1993: Estimates of horizontal divergence and vertical velocity in the equatorial Pacific. J. Phys. Oceanogr., 23, 601607.

Qiao, L., and R. H. Weisberg, 1995: Tropical instability wave kinematics: Observations from the Tropical Instability Wave Experiment. J. Geophys. Res., 100, 8677-8693.

— and - 1997: The zonal momentum balance of the Equatorial Undercurrent in the central Pacific. J. Phys. Oceanogr., 27, $1094-1119$

— vations from the Tropical Instability Wave Experiment. J. Phys. Oceanogr., 28, 345-360.

Quay, P. D., M. Stuiver, and W. S. Broecker, 1983: Upwelling rates for the equatorial Pacific Ocean derived from the bomb ${ }^{14} \mathrm{C}$ distribution. J. Mar. Res., 41, 769-792.

Reynolds, R. W., and T. M. Smith, 1994: Improved global sea surface temperature analysis using optimum interpolation. J. Climate, 7, 929-948.

Robinson, A. R., 1966: An investigation into the wind as the cause of the Equatorial Undercurrent. J. Mar. Res., 24, 179-204.

Roemmich, D., 1983: The balance of geostrophic and Ekman transports in the tropical Atlantic Ocean. J. Phys. Oceanogr., 13, $1534-1539$.

Seager, R., and R. Murtugudde, 1997: Ocean dynamics, thermocline adjustment, and regulation of tropical SST. J. Climate, 10, 521534.

Stommel, H., 1960: Wind-drift near the Equator. Deep-Sea Res., 6, 298-302.

Tennekes, H., and J. L. Lumley, 1972: A First Course in Turbulence. The MIT Press, $300 \mathrm{pp}$.

Weingartner, T. J., and R. H. Weisberg, 1991a: On the annual cycle of equatorial upwelling in the central Atlantic Ocean. J. Phys. Oceanogr., 21, 68-82.

-, and - 1991b: A description of the annual cycle in sea surface temperature and upper ocean heat in the equatorial Atlantic. J. Phys. Oceanogr., 21, 83-96.

Weisberg, R. H., J. C. Donovan, and R. D. Cole, 1991: The Tropical 
Instability Wave Experiment (TIWE) Equatorial Array: a report on data collected using subsurface moored acoustic Doppler current profilers, May 1990-June 1991. Department of Marine Science, University of South Florida, $84 \mathrm{pp}$.

Wunsch, C., 1984a: An eclectic Atlantic Ocean circulation model. Part I: The meridional heat flux. J. Phys. Oceanogr., 14, 17121733.

1984b: An estimate of the upwelling rate in the equatorial Atlantic Ocean based on the distribution of bomb radiocarbon and quasigeostrophic dynamics. J. Geophys. Res., 89, 79717978.
Wyrtki, K., 1981: An estimate of equatorial upwelling in the Pacific. J. Phys. Oceanogr., 11, 1205-1214.

- and G. Eldin, 1982: Equatorial upwelling events in the central Pacific. J. Phys. Oceanogr., 12, 984-988.

, and B. Kilonsky, 1984: Mean water and current structure during the Hawaii-to-Tahiti Shuttle Experiment. J. Phys. Oceanogr., 14, $242-254$.

Yang, Y. J., T. Y. Tang, and R. H. Weisberg, 1997: Basin-wide zonal wind stress and ocean thermal variations in the equatorial Pacific. J. Geophys. Res., 102, 911-927. 